\title{
Economic preferences and trade outcomes
}

\author{
Alex Korff ${ }^{1} \cdot$ Nico Steffen ${ }^{2}$ (1)
}

Accepted: 13 July 2021 / Published online: 4 September 2021

(C) The Author(s) 2021

\begin{abstract}
Integrating the Global Preference Survey (GPS) and its data of unique scope on national preference structures in patience, risk attitude and reciprocity into a gravity framework, this paper is the first to explore a potential influence on international trade outcomes of economic and social preferences in a unified setting. Adding to the evidence on preferences' importance for aggregate outcomes, the authors find marked differences in trade flows and relationships, both on the country-level and between bilateral partners. Their main results suggest that countries differing in their willingness to behave negatively reciprocal tend to trade significantly less amongst each other due to the destabilizing effect of unexpected punishments. On the other hand, countries that are patient or risk-averse tend to shift towards exporting more differentiated goods as opposed to homogeneous goods and vice versa. We propose term and risk transformation considerations as the driving mechanisms for this relationship.
\end{abstract}

Keywords Trade determinants · Non-tariff barriers · Economic preferences · Sociocultural variation

JEL Classification F10 $\cdot \mathrm{F} 14 \cdot \mathrm{D} 01 \cdot \mathrm{D} 91 \cdot \mathrm{Z} 10$

\section{Introduction}

International trade, while recently beleaguered by protectionism and trade wars, is established in economics as an engine of growth, welfare and progress. Its potential for division of labour, specialisation and efficient use of capital is unmatched by any domestic policy, which would inevitably be faced with rigidities and restrictions in these factors. Nonetheless, the intensity of international trade has been stagnant below assumed efficient levels even before the protectionist trends of the present.

Nico Steffen

steffen@dice.hhu.de

1 Heinrich Heine University of Düsseldorf, Düsseldorf, Germany

2 Düsseldorf Institute for Competition Economics (DICE), Düsseldorf, Germany 
The causes for these so-called "dark" trade costs partly remain unknown, preventing both a solution and a more optimal outcome.

In response to these anomalies, the trade literature has expanded the concept of economic gravity, based on market size, output and "hard" barriers-i.e. geographic distance and tariffs - by "soft" barriers such as cultural factors. These are based on persistent differences and similarities across countries, ranging from language or colonial history to shared values and even genetic distance. The proposed underlying mechanisms include facilitated communication, reduced informational frictions or historically established ties, but also even less tangible aspects such as shared beliefs and norms, that could foster bilateral trust, for example.

By linking data and insights from behavioural economics to the trade context, this paper proposes novel additional mechanisms connecting culture with trade outcomes. To this end, term (patience) and risk preferences as well as reciprocal behaviour are incorporated into a gravity analysis using the novel GPS preference data by Falk et al. (2018). These preferences, likely shaped by culture and society within a given country, might affect negotiations between firms and agents of different nations. They inform their time horizons, influencing discounted values of a deal, their willingness to risk investment into a trade relationship and their responses to (non-)cooperative behaviour. Each of these four aspects could help explain trade outcomes and anomalies in volume between economically similar country pairs.

Analytically, this paper is the first - to the best of the authors' knowledge- to join the gravity model for trade with specific data on such behavioural preferences at the population level. That is, the observed preferences directly relate to economic decisions in the realm of contract theory and incomplete contracts. The paper expands the gravity model by a new dimension of soft barriers, which also provide a possible explanation for the effect of cultural distances on trade outcomes and for "missing trade" as well as "dark trade costs".

Preferences are integrated into the gravity framework using a two-step approach: Distances in preferences across countries are incorporated into a standard gravity model to measure the effects of bilateral differences in reciprocity as well as term and risk transformation considerations. The national preference levels, meanwhile, are analysed by decomposing the multilateral resistance terms of the gravity equation, a country's overall propensity towards trade, thus discerning potential shifts in trade inclination associated with specific national preference leanings. The GPS is particularly well-suited to this analysis because of its broad scope and quality, covering 76 countries through nationally representative surveys on these preferences and experimental validations for them.

This analysis finds that the distance in reciprocity between countries and term and risk orientation levels of a given country affect trade outcomes. Specifically, a distance in negative reciprocity between countries, i.e. the willingness to engage in costly punishment, is detrimental to export volumes by introducing unexpected costs in case of transaction issues.

The national level of long-term orientation and higher levels of risk aversion, meanwhile, lower the average trade barriers for differentiated goods, while raising them for non-differentiated ones. Less risk aversion and shorter term orientation have the opposite effects. This reflects term and risk transformation concerns by 
national players, wherein a product mix is selected whose trade and contract conditions reflect term and risk profiles. That is, the longer the term orientation the more complex and differentiated the product mix, and: the more risk-averse a country, the less volatile and more differentiated the produced goods. Lastly, preference effects are overall stronger for exporters, differentiated goods and OECD-countries, indicating the link between preferences and negotiation intensity as well as the financial risks being placed on the exporter.

The rest of the paper is structured as follows. Section 2 relates the paper to the existing literature, leading into Sect. 3 which summarizes the hypotheses of the analysis. Section 4 introduces the data and the empirical strategy, whose results are reported in Sect. 5. Section 6 discusses a set of robustness checks and their results. Finally, Sect. 7 concludes with a short discussion on the results and considerations for further research.

\section{Related literature}

This paper aims to link two fields of economic literature: the analysis of trade flows, especially on soft barriers to trade, and the literature on behavioural economics. Contract theory is utilised as the mechanism for this conjunction.

Our analysis builds on previous analyses of trade finance and the incomplete contracts governing trade, which have touched upon the behavioural considerations at the core of this paper. Trade finance explicitly deals with the management of risk in a trade context. Therein, risk is often placed primarily on the exporter given the wide prevalence of Open Account (OA) arrangements, i.e. the importer paying only after having received the goods (Ahn 2011; Antras 2003). Given these risks and uncertainties, it is unsurprising that complex, but (still) incomplete contracts govern the actual trade interactions. In addressing these complex contracts and their dynamic nature, Defever et al. (2016) and Kukharskyy (2016) have shown that only sufficiently patient firms may establish efficient long-term supplier collaborations. Findings by Araujo et al. (2016); Aeberhardt et al. (2014) and Rauch and Watson (2003) point to relationships being developed slowly, starting with small test orders until a relationship is established, reflecting reciprocity considerations. We build upon both of these relationships by attempting to investigate their more abstract, global effects using the GPS.

In regard to the broader trade literature, we contribute to the shift in discussion from conventional drivers like size and transportation costs to "missing trade" (Trefler 1995) and "dark" trade costs (Head and Mayer 2013) by proposing a novel influence in the form of national preference leanings and a simple mechanism by which its influence would occur. Closest to our analysis are Frank (2018) and Jaeggi et al. (2018) who analyse cultural attitudes as factors for overall economic development. These are future orientation and other measures from the GLOBE survey in the former and a dyadic values distance measure computed using the World Values Survey in the latter case. Genetic and values distances are consequently used as robustness checks in this analysis. However, we differ from their approaches in two ways: by also considering potential positive effects of such divergence and by 
proposing a channel for these effects by introducing behavioural concepts and contract theory. We follow previous analyses on cultural differences such as Melitz and Toubal (2014), who analysed the effects of a shared language and revealed a channel of shared ethnicity in the process. Another example would be Lameli et al. (2015), who discovered a trade-boosting effect between German regions sharing similar dialects. Similarly, Felbermayr and Toubal (2010) have investigated a proxy for cultural proximity as a determinant of trade flows and Fensore et al. (2017) have introduced genetic distance as a measure to this end as well. ${ }^{1}$ Lastly, bilateral trust, which could also be considered a preference, has been extensively studied in the trade context, for example by Guiso et al. (2009) or Yu et al. (2015), who find positive effects of trust on trade activity.

Naturally, our analysis also connects to the behavioural economics literature leading up to the GPS study itself (Falk et al. 2016, 2018) and to research by Dohmen et al. (2016) linking patience with national economic development. Thereby, we also relate to a broader literature linking the preferences also measured in the GPS to individual outcomes. This includes Sutter et al. (2013) who link time and risk preferences to saving and smoking decisions, Kihlstrom and Laffont (1979) who investigate entrepreneurial activity with regards to the risk preferences of the players, and Fehr et al. (1997); Fehr and Gächter (2000, 2002) and Nikiforakis (2008) who all investigate the effects of reciprocity preferences on collective action and their outcomes. Here, we contribute to the literature by observing expressions of these individual decisions and outcomes at the aggregate level.

\section{Hypotheses}

In this section, the hypothetical mechanisms by which preferences might affect trade outcomes are presented and their directions summarised. For each of the four GPS dimensions patience, risk, positive and negative reciprocity, two effects are considered: the level of a given country and bilateral differences across countries. That is, a preference could matter unilaterally and shift a country's general attitude towards trade or it could matter only in contrast to the partner's preference distributions. The resulting dimensions and their proposed effect directions are displayed in Table 1 at the end of this section.

As a simple guiding structure, a Home producer looking to export to a Foreign distributor is considered. Alternative settings, e.g. a Home firm looking for a supplier or the viewpoint of the Foreign firm, could be conceived analogously, but the prevalence of Open Account (OA) contracts usually burdens the risk on the exporter. ${ }^{2}$ Thus, it is the Home producer who has the largest incentives to carefully

\footnotetext{
1 The latter's general (causal) influence has been challenged by Giuliano et al. (2013), however.

2 While Importers in countries with a low institutional quality, i.e. weak contract enforcement, may have to take on the risk position to initiate a relationship using CIA payments, exporters often switch back to open account terms even in these cases, once the relationship has been established and trust formed (cf. Antras and Foley 2015). Hence, this setting is not considered to be the norm here.
} 
consider his trade relationships, implying a potentially larger role of exporter's preferences, as well.

In this setting, producers and distributors have to choose between domestic and international relationships, wherein the latter are associated with greater uncertainties due to a - typically - lower knowledge of these partners and their markets. These uncertainties include the timing of payments as well as default and recoupment risks, for which the players would formulate expectations and, in a next step, expected values for a given trade relationship. These calculations and thus the outcomes might be shaped or influenced by the preference leanings of the players involved. In the following, the rationale for each of the four dimensions investigated in this analysis is provided.

Patience Patience measures the willingness to forego short-term profits for higher gains in the long-run and therefore factors into the evaluation of the timing of payments in the setting outlined above. Higher levels of patience should imply a lower discount (higher interest) rate, i.e. a higher tolerance for delayed payments, and consequently benefit trade volumes and intensity by raising the expected value of trade.

Another rationale for this hypothesis is the understanding of trade as a means to achieve efficiency gains by constructing international supply and distribution networks, allowing greater specialization. Since the construction of these networks, from contract negotiations to physical construction and transport times, requires time and effort, more patient agents would be more likely to engage in these activities than impatient agents. Conversely, impatient agents would be more likely to engage with local partners despite a potential long-term disadvantage.

This mechanism could also be interpreted as a form of comparative advantage, in which the opportunity costs for production are lowest for those goods which best fit a country's level of patience by avoiding costly term transformations, inviting specialization into these goods. The gains from that specialization would manifest best between differently patient players exploiting their respective comparative advantages. Hence, these gains would define the effect of distances in patience on trade and should be positive. However, the more pronounced effect of a comparative advantage is the change in the composition and structure of trade, which might overshadow a potential bilateral increase in volumes.

Risk-taking The GPS risk preference can be understood as an inverse measure of the average risk premium a given population is willing to pay. For highly risk-tolerant societies, this measure can take a negative value, while it is positive for the average population. With regards to trade outcomes, less risk-aversion should facilitate the formation of trade relations as it would heighten the tolerance for trade-associated risks and uncertainties such as defaults on payments. For exporters in particular, this tolerance would be required so as to compensate for the risks placed on them by the structure of trade finance.

However, considering the greater picture of trade, it might be risk-minimising to diversify into a multitude of international relationships, lowering the exposure to local shocks and individual contracts. Note that this diversification argument applies to both securing access to inputs and to maintaining steady sales and cashflows. 
Table 1 Summary of the hypotheses for preferences

\begin{tabular}{lll}
\hline Dimension & \multicolumn{2}{l}{ Effect on Trade Values } \\
\cline { 2 - 3 } & Preference Level & $\begin{array}{l}\text { Distance in } \\
\text { Preference }\end{array}$ \\
\hline Patience & + & $+/ 0$ \\
Risktaking & $+/-$ & + \\
Pos. Recip. & + & + \\
Neg. Recip & $+/-$ & - \\
Overall & & -
\end{tabular}

This table summarizes the hypothesized effect of the four preference dimensions patience, risk attitude, positive and negative reciprocity on trade outcomes as well as for the average bilateral distance over all dimensions. It provides hypotheses for both the unilateral level of a preference dimensions and the bilateral distance between two countries in that dimension

+ implies a positive relationship, - implies a negative one, $+/-$ an unclear relationship and $+/ 0$ one that could be positive or non-significant. An empty entry signals that no effect can exist

Hence, the effect of unilateral national risk-taking levels on trade outcomes is unclear ex ante.

On the other hand, the effect of bilateral distances in risk attitudes on trade should be positive. A divergence in risk perceptions should allow for forms of arbitrage and for risk transformation, similar to the hypothesis for patience, with regards to the product mix of the players of a given country pair. This, too, can be viewed as a form of comparative advantage, wherein less risk-averse players have lower opportunity costs in producing goods with a higher perceived commercial risk and viceversa. Trade then generates efficiency gains by reducing the amount of risk premia needed to facilitate overall production.

Positive reciprocity Positive reciprocity is the willingness to reward cooperative behaviour and positive actions, i.e. a propensity to "return a favour". In general, the presence of a more positively reciprocal player should stabilize commercial agreements by inducing cooperation. This can be achieved through positive feedback loops caused by reliable and timely deliveries and payments, which would build up goodwill on both sides of the relationship. ${ }^{3}$ In contract terms, positively reciprocal actions could lower the perceived risk of defaults or assume the shape of more accommodating terms of payment within an active and ongoing relationship, thus lowering costs and building trust.

\footnotetext{
${ }^{3}$ Corresponding results or interpretation are common in the literature. Fehr et al. (1997) have stressed the importance of reciprocity in non-enforceable contracts especially, while Gächter and Herrmann (2009) showed that positive reciprocity may induce selfish types to cooperate. Cable and Shane (1997) propose positively reciprocal cooperation as a key aspect in an entrepreneur's efforts to acquire capital and develop alliances with larger companies.
} 
Consequently, the distance in positive reciprocity should have a positive effect due to the implied presence of one highly positively reciprocal partner. In such a relationship, the reciprocal behaviour of that partner would be viewed akin to a standard gift exchange (cf. Akerlof 1982) and thus strengthen the relationship between the players. Moreover, the effect of positive reciprocity can only manifest within existing relationships. Hence, it would neither shift the overall approach to trade nor the extensive margin of trade, defined here as the number of bilateral non-zero trade flows on the three-digit SITC industry level.

Negative reciprocity Negative reciprocity describes a willingness to conduct costly punishment of non-cooperative behaviour and negative actions. A hypothesis on its effects is complicated. On one hand, higher levels imply a willingness to punish deviation from contracts and agreements-even beyond a monetarily rational level-,thus raising the cost of a breach of contract once it has been established. While this might partially deter some initial agreements in the first place, the prospect of a more credible punishment could help to prevent deviation by raising the costs to the partner deviating from the contract. In this way, it may foster the establishment of persistent trade relationships. Dohmen et al. (2008), for example, highlight this ability to make credible threats as a potential bargaining advantage.

However, this seems to hold true for milder forms of negative reciprocity only. In its strongest forms-decisively taking revenge and anti-social punishment-, negative reciprocity may actually hinder coordination and cooperation (Gächter and Herrmann 2009; Herrmann et al. 2008). In a contract framework, the risks associated with the threat of punishment could become higher than the prospective gains from trade, causing a rational player to abstain from the deal. As an example for this perspective, Caliendo et al. (2012) observe that a propensity to take revenge negatively affects the probability of staying in entrepreneurship, suggesting that high levels of negative reciprocity reflect non-cooperation and reduce one's own profits.

More importantly, if partners differ in negative reciprocity, the actions of the more negatively reciprocal partner might antagonize or alarm the less reciprocal partner. Thus, larger distances in negative reciprocity are expected to reduce bilateral trade. For the level effect, no clear prognosis is possible.

Overall Bilateral Distance Following the literature on shared characteristics in trade such as language, ethnicity and culture, the effect of overall preference distances between two countries is also analysed. This serves two purposes. First, it allows a comparison to studies regarding such shared characteristics and to control for a potential correlation with them. Second, it allows for testing the hypothesis that partners with more similar preference sets would be more likely to trade with one another solely on account of that greater similarity causing affinity. Given the diverging proposed directions for the preference dimensions specified above, such an effect is unlikely to emerge at the overall level. 


\section{Data and empirical strategy}

Mapping and isolating the potential impact of preferences on trade requires a comprehensive, three-part data set consisting of the GPS' preference data, the corresponding trade data and a set of cultural and institutional controls. The following subsections will be dedicated to describing the data used and the empirical strategy.

\subsection{Data}

Preference Data The main variables of interest are the GPS' results detailing a fourdimensional preference structure for 76 countries: patience, risktaking, positive and negative reciprocity. Patience is therein understood as a broader measure of term orientation or time discount considerations, whereas risk assesses the average risk premium of a given population. Positive reciprocity is the willingness to reward cooperative behaviour and, consequently, negative reciprocity the willingness to conduct costly punishment of non-cooperative or deviant behaviour. ${ }^{4}$ All preferences are considered to be persistent, underlying convictions or notions, related to upbringing, education, norms and other societal trends.

The GPS was conducted alongside the 2012 Gallup World Poll, utilising the infrastructure and scope of that survey to gain both coverage and size. The Gallup World Poll interviewed representative samples of at least 1000 persons per covered country and uses tried weighting techniques for these samples to match a nation's population. The GPS' data covers all important global economies with the possible exception of Africa. Around ninety percent of world population and GDP lie within the sample borders. Africa's coverage is less dense than for the other continents, but both Sub-Saharan and North African countries are included, which permits their use without disregarding the structural differences imposed by the Sahara desert (see Falk et al. 2018). This scope permits conclusions beyond the traditionally available data from more developed countries only. This size and the World Poll's methodology elevate the GPS above previously available measures.

Additionally, the survey items-except for negative reciprocity-are experimentally validated (see Falk et al. 2018), in that incentivized experiments were conducted to evaluate the fit between survey answers and revealed preferences in the experiment. This factor differentiates the GPS from other typically questionnaireonly surveys of similar intent by contextualizing the preferences as economic. The focus is shifted from abstract cultural measures and perceptions to their role in decision-making. Via that channel, these preferences inform negotiations, defining term and risk profiles and behaviour in interaction.

As for the preferences themselves, they are provided in a normalized distribution, calculated in a three-step procedure. First, individual-level data on the experimental and survey data is combined using weights obtained by OLS regression on behavior

\footnotetext{
4 The GPS also includes assessments of the preferences altruism and trust, which were not used in this analysis. For further information, see the Appendix Table 7.
} 
observed in the experimental validation study conducted beforehand (see Falk et al. 2016). Secondly, these measures are standardized with regard to the full sample of around 80,000 individuals from all 76 countries. Hence, each preference is, by design, of mean zero and standard deviation one on individual levels. Third-and lastly - individual-level data of each country is aggregated to the national average using Gallup World Poll sampling weights. As a result, the national averages are representative of a respective country's population and similarly have means close to zero. Their standard deviations lie between 0.27 and .37 , with explicit minima and maxima diverging from symmetry (see Table 2). Figure 1 relates GPS values to national export volumes (relative to GDP), providing an overview of the country's preference distributions. ${ }^{5}$

Culture, Politics and Institutions Preferences might be correlated with other cultural variables. They could also interact with institutional settings, as has been found for trust and rule of law (Yu et al. 2015), or the overall economic situation. To account for these potential biases, a broad range of cultural, historic, political or economic indicators supplements the preference data. This includes population, GDP and other national characteristics from the CEPII (Head et al. 2010; Head and Mayer 2014) as well as information on geography and colonial history (Mayer and Zignago 2011). ${ }^{6}$ Information on regional trade agreements is extracted from Egger and Larch (2008).

Data on linguistic similarities is integrated using data from Melitz and Toubal (2014), who provide and compare multiple measurements for the resulting ease of communication. In the same vein, information regarding cultural, religious and genetic distance from Spolaore and Wacziarg $(2016,2018)$ is used to account for the more general effects of alien- or likeness. The Dyadic Values Distance measure created by Jaeggi et al. (2018) and drawn from the World Values Survey is included for contrast and comparison; as are the Hofstede dimensions (see Hofstede et al. 2010).

For political and institutional influences, the Polity scores (2018), Freedom House indices (2018), and Worldwide Governance Indicators (Kaufmann et al. 2009) are used. These assess democratic or autocratic leanings and civil liberties as well as issues of politic representation, respectively. Thus, the measures can be used as proxies for legal rights and personal freedom, which might both impact negotiation behavior and outcomes.

Trade Data The trade data used in the analysis is obtained from UN Comtrade for 2012, the year in which the GPS had been conducted, at the 3-digit industry level

\footnotetext{
5 Table 7 and Fig. 2 in the Appendix analogously summarise the preference distances and their relationships to trade volumes.

6 Additional data on country terrain is drawn from Nunn and Puga (2012), who measure the ruggedness - i.e. differences in altitude - within a country, a potential measure for physical trade barriers. However, these measures were excluded from the final results to consolidate variables used in the second stage on account of the low number of observations. Since their exclusion does not alter results significantly, this seemed an acceptable compromise. Nonetheless, their potential influence had to be controlled for.
} 

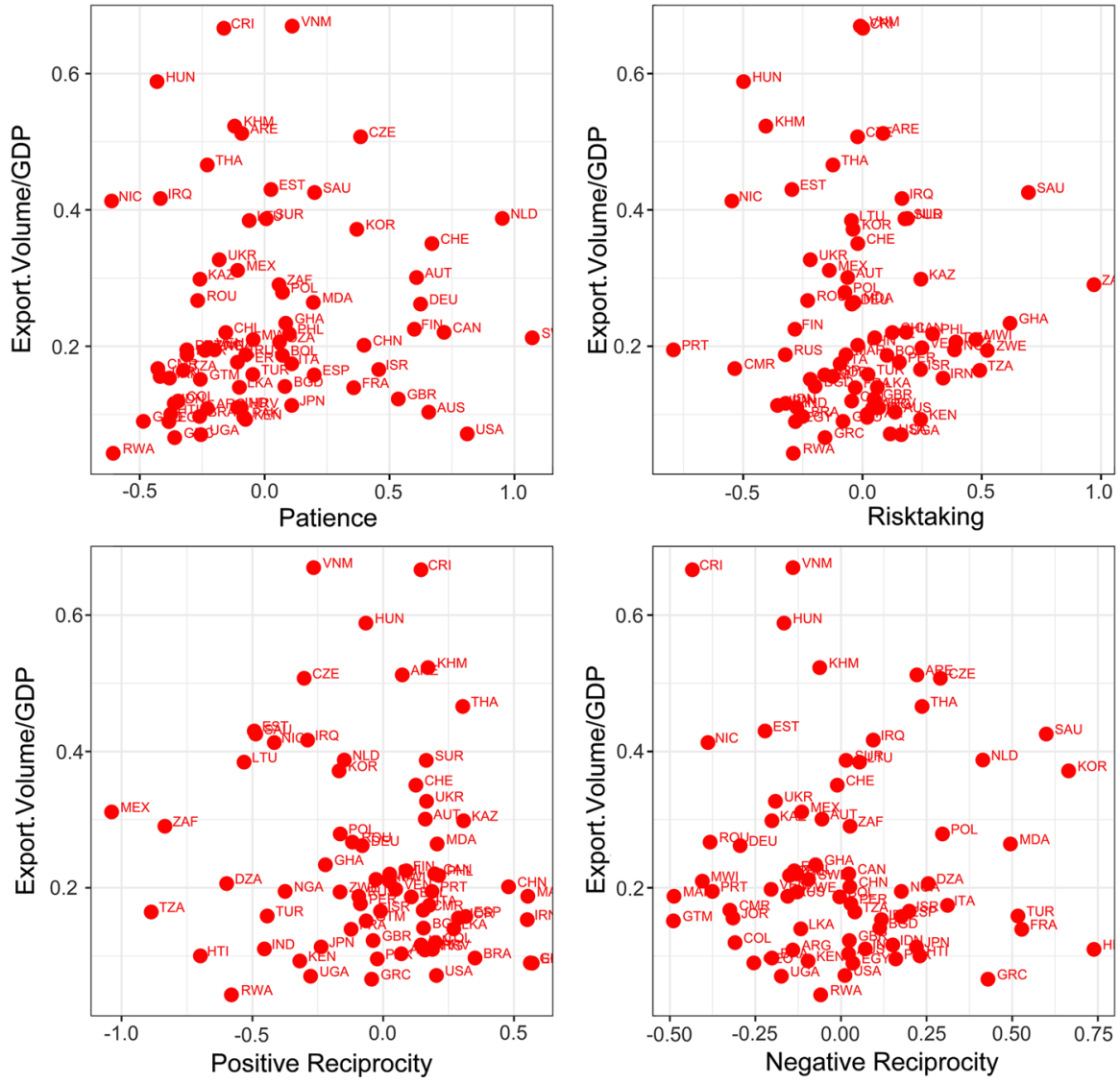

Fig. 1 Preference structure and trade volume. Notes: Relationship between the export values, normalised by GDP, and GPS preference values for all countries in the GPS for which trade volumes can be computed

Table 2 Descriptive statistics of the GPS variables

\begin{tabular}{lllllll}
\hline Statistic & Mean & St. Dev. & Min & Max & Top 3 & Bottom 3 \\
\hline Patience & 0.001 & 0.377 & -0.613 & 1.071 & SWE, NLD, USA & NIC, RWA, GEO \\
Risktaking & 0.006 & 0.298 & -0.792 & 0.971 & ZAF, SAU, GHA & PRT, NIC, CMR \\
Pos. Recip. & -0.042 & 0.344 & -1.038 & 0.570 & EGY, GEO, MAR & MEX, TZA, ZAF \\
Neg. Recip & 0.007 & 0.276 & -0.489 & 0.739 & HRV, KOR, SAU & GTM, MAR, CRI
\end{tabular}

Each of the preferences is normalized at the individual level, then aggregated to national averages using Gallup World Poll weights. Hence, their means are close to but not exactly zero. Standard deviations range from 0.275 to 0.37 , as substantial variation occurs between individuals and within nations. Minima and maxima highlight an asymmetry in preference distributions. For each preference, the three countries with the highest and lowest preference values are provided in order 
Table 3 Estimation of aggregated bilateral exports

\begin{tabular}{|c|c|c|c|c|c|}
\hline & $\begin{array}{l}\text { Basic Grav. } \\
\text { (1) }\end{array}$ & $\begin{array}{l}\text { Agg. Pref. } \\
\text { Dist. } \\
(2)\end{array}$ & $\begin{array}{l}\text { Agg. Pref. } \\
\text { Dist } \\
(3)\end{array}$ & $\begin{array}{l}\text { Single Pref. } \\
\text { Dist. } \\
\text { (4) }\end{array}$ & $\begin{array}{l}\text { Single Pref. Dist. } \\
\text { (5) }\end{array}$ \\
\hline ldist & $\begin{array}{l}-0.60^{* * *} \\
(0.06)\end{array}$ & $\begin{array}{l}-0.60^{* * *} \\
(0.07)\end{array}$ & $\begin{array}{l}-0.59^{* * *} \\
(0.06)\end{array}$ & $\begin{array}{l}-0.61^{* * *} \\
(0.06)\end{array}$ & $\begin{array}{l}-0.59^{\text {**** }} \\
(0.06)\end{array}$ \\
\hline contig & $\begin{array}{l}0.42^{* *} \\
(0.15)\end{array}$ & $\begin{array}{l}0.43^{* *} \\
(0.15)\end{array}$ & $\begin{array}{l}0.48^{* * *} \\
(0.14)\end{array}$ & $\begin{array}{l}0.42^{* *} \\
(0.14)\end{array}$ & $\begin{array}{l}0.48^{* * *} \\
(0.14)\end{array}$ \\
\hline colony & $\begin{array}{l}0.29^{* *} \\
(0.11)\end{array}$ & $\begin{array}{l}0.29^{* *} \\
(0.11)\end{array}$ & $\begin{array}{l}0.32^{* *} \\
(0.11)\end{array}$ & $\begin{array}{l}0.29^{\text {** }} \\
(0.11)\end{array}$ & $\begin{array}{l}0.33^{* *} \\
(0.10)\end{array}$ \\
\hline rta & $\begin{array}{l}0.28^{* *} \\
(0.10)\end{array}$ & $\begin{array}{l}0.27^{* *} \\
(0.10)\end{array}$ & $\begin{array}{l}0.32^{* * *} \\
(0.09)\end{array}$ & $\begin{array}{l}0.29^{\text {** }} \\
(0.10)\end{array}$ & $\begin{array}{l}0.35^{* * *} \\
(0.09)\end{array}$ \\
\hline $\operatorname{lng}$ & $\begin{array}{l}0.05 \\
(0.15)\end{array}$ & $\begin{array}{l}0.03 \\
(0.15)\end{array}$ & $\begin{array}{l}-0.08 \\
(0.12)\end{array}$ & $\begin{array}{l}0.04 \\
(0.14)\end{array}$ & $\begin{array}{l}-0.06 \\
(0.13)\end{array}$ \\
\hline dpref & & $\begin{array}{l}-0.20 \\
(0.38)\end{array}$ & $\begin{array}{l}-0.44 \\
(0.30)\end{array}$ & & \\
\hline comleg & & & $\begin{array}{l}0.17^{*} \\
(0.07)\end{array}$ & & $\begin{array}{l}0.15^{*} \\
(0.07)\end{array}$ \\
\hline leg.qlt & & & $\begin{array}{l}0.15^{* * *} \\
(0.02)\end{array}$ & & $\begin{array}{l}0.15^{* * * *} \\
(0.03)\end{array}$ \\
\hline dpati & & & & $\begin{array}{l}0.03 \\
(0.12)\end{array}$ & $\begin{array}{l}-0.16 \\
(0.10)\end{array}$ \\
\hline drisk & & & & $\begin{array}{l}0.36 \\
(0.27)\end{array}$ & $\begin{array}{l}0.52^{\dagger} \\
(0.28)\end{array}$ \\
\hline dposrec & & & & $\begin{array}{l}-0.00 \\
(0.16)\end{array}$ & $\begin{array}{l}-0.04 \\
(0.18)\end{array}$ \\
\hline dnegrec & & & & $\begin{array}{l}-0.62^{* * *} \\
(0.15)\end{array}$ & $\begin{array}{l}-0.53^{* *} \\
(0.16)\end{array}$ \\
\hline Observations & 5112 & 5112 & 5112 & 5112 & 5112 \\
\hline Deviance & $4785 \times 10^{9}$ & $4781 \times 10^{9}$ & $4646 \times 10^{9}$ & $4683 \times 10^{9}$ & $4562 \times 10^{9}$ \\
\hline $\begin{array}{l}\text { Null Devi- } \\
\text { ance }\end{array}$ & $52347 \times 10^{9}$ & $52347 \times 10^{9}$ & $52347 \times 10^{9}$ & $52347 \times 10^{9}$ & $52347 \times 10^{9}$ \\
\hline Exp./Imp. FE & YES & YES & YES & YES & YES \\
\hline
\end{tabular}

The estimation on aggregated bilateral exports, $X_{i j}$, is conducted via PPML. The variables of interest are the distances in preferences, included as an unweighted average dpref in $(2,3)$ and as single variables dpati, drisk, dposrec, dnegrec $(4,5)$. A dummy for common legal systems comleg and a measure for differences in legal quality leg.qlt are included in models (3) and (5) due to their potential impact on negotiations, the channel of interest. Model (1) is a standard gravity equation for comparison. Standard errors are clustered to Importer and Exporter fixed effects

${ }^{* * *} p<0.001,{ }^{* *} p<0.01,{ }^{*} p<0.05,{ }^{\dagger} p<0.1$

(SITC, Rev. 4). Flows are measured using import data, which is considered more accurate due to customs and tariff requirements of the receiving country. All 240 goods categories are observed for 68 countries of the GPS. The disaggregated data 
is used to divide trade flows into listed, reference priced and differentiated goods according to Rauch (1999), as these groups might respond differently.

A subset of ten nations available in the GPS-Afghanistan, Botswana, Cameroon, Haiti, Iran, Iraq, Kenya, Morocco, Philippines and Venezuela-, have not yet reported for 2012. Their flows are calculated using export data from their 66 partner countries $^{7}$. Additionally, Bosnia-Herzegovina and Serbia are dropped due to the risk of confounding with Yugoslavia for several cultural variables, while Afghanistan is dropped due to a general lack in controls.

Given these corrections, the final dataset contains 73 countries from all continents, yielding 5256 exporter-importer pairs and 1,261,440 bilateral good-specific trade flows. Of these, 35.8 percent are non-zero, whereas the average value of a bilateral good-specific trade flow amounts to 8.9 million US-Dollar. The average country trades with 67 out of 72 potential partners and in 86 out of 240 goods categories. ${ }^{8}$

\subsection{The model}

The analysis is built upon the Gravity framework by Anderson and van Wincoop (2003) and its expansions by Head and Mayer (2014); Yotov et al. (2016) and Santos Silva and Tenreyro (2006); Santos Silva et al. (2014). Therein, international trade $x_{i j}$, between exporter $i=1, \ldots, I$ and importer $j=1, \ldots, J$, is modeled as:

$$
x_{i j}=\underbrace{\frac{Y_{i}}{\Omega_{i}}}_{S_{i}} \underbrace{\frac{X_{j}}{\Phi_{j}}}_{M_{j}} \phi_{i j}
$$

$Y_{i}$ and $X_{j}$ are the total values of exporter production and importer expenditure, respectively, and $\phi_{i j}$ describes the bilateral trade costs between $i$ and $j$, which are assumed to be symmetric. $\Omega_{i}$ and $\Phi_{j}$ represent the multilateral resistance terms, a representation of the average trade barriers faced by exporters. These terms can be defined as:

$$
\Omega_{i}=\sum_{l} \frac{\phi_{i l} X_{l}}{\Phi_{l}} \text { and } \Phi_{j}=\sum_{l} \frac{\phi_{l j} Y_{l}}{\Omega_{l}}
$$

$\Omega_{i}$ is the expression of an exporter $i$ 's average cost of exporting to any other country, and $\boldsymbol{\Phi}_{j}$ correspondingly the average cost of importing into country $j .{ }^{9}$ An alternative designation is that of outward and inward multilateral resistance term, respectively

\footnotetext{
7 See the Appendix for further detail regarding potential bias inherent in the use of reported data from both trade flows. Note also that trade between these countries is missing entirely, causing potentially nonnegligible bias.

${ }^{8}$ Note that only 72 countries can be used in the main analysis due to lacking control variables.

9 More precisely, the average trade barrier of one exporter (importer) is constructed as the sum of bilateral trade costs weighted by the expenditure (consumption) share of each flow and the respective partner's own average import (export) costs. In its pure form, this could only be solved iteratively or given a complete set of trade costs.
} 
(see Donaubauer et al. 2018). With the Gravity framework's three cost parameters, $\phi_{i j}, \Omega_{i}$ and $\Phi_{i}$, the potential effects of GPS preferences can be studied. Differences between them could influence transaction costs by affecting negotiations through aligning term and risk transformation objectives or reciprocal gestures. These preference distances thus constitute a bilateral cost parameter $\left(\phi_{i j}\right)$, which also permits comparison with the similarly modelled cultural differences. Preference leanings, meanwhile, could influence the overall openness to trade of a given population by defining its outlook. They can be analysed only akin to unilateral economic variables, i.e. as part of the resistence terms $\Omega_{i}$ and $\Phi_{j}$.

Intensive Margin Both multilateral resistance terms are typically modelled as fixed effects, $S_{i}$ and $M_{j}$ (see Eq. 1), due to computational and information restrictions. This method also accounts for unobserved heterogeneity in trade determinants. Given the assumption of persistence for preferences, a country's preference leanings would be subsumed under the fixed effects. However, these fixed effects and its components can be analysed in a two-step approach using a Gravity specification first and OLS on the estimated fixed effects second (cf. Donaubauer et al. 2018; Head and Mayer 2014). Thus, unilateral preference levels can be analysed in this trade context. In accordance with the wider literature, that specification is estimated using Pseudo Poisson Maximum Likelihood (PPML) for consistency in the presence of heteroskedasticity and zero trade flows (Santos Silva and Tenreyro 2006). The first step estimator is defined as:

$$
x_{i j}=\exp \left(\left|z_{i}-z_{j}\right| \boldsymbol{\beta}+S_{i}+M_{j}+\phi_{i j}^{\prime} \gamma\right)+\epsilon_{i j},
$$

where $S_{i}$ and $M_{j}$ are the exporter and importer fixed effects-or average trade barriers-, including preference levels. $\phi_{i j}$ is a vector of bilateral (dyadic) trade cost variables. $x_{i j}$ is the volume of exports from country $i$ to country $j$, the intensive margin of trade. $\left|z_{i}-z_{j}\right|$ is a vector of the preference distances between a country pair. Each of the four preferences patience, risk, positive and negative reciprocity is included separately. The use of absolute distances serves three purposes. First, it distinguishes the distances from the unilateral levels (leanings), allowing effect decomposition. Second, it abstracts from the direction of distances, which might conflate effects otherwise due to its correlation with the levels ${ }^{10}$. Third, it is necessary as the provided GPS variables are normalized, for which reason normal differences cannot be estimated. $^{11}$

The gravity equations are applied to both the total bilateral trade volumes and separate volumes for differentiated and non-differentiated goods. This split accounts for the fact that negotiations, the effect channel, would play a more important role for differentiated goods than for listed or reference-priced commodities. The more goods diverge from a global standard, the more details need to be covered in the

\footnotetext{
10 Inclusion of these directions as dummy variables does not alter results, however.

11 In the robustness section, alternative approaches are tested: the maximum and minimum preference values of each pair, an inclusion of the direction, and the maximum and minimum values if they are more than one standard deviation distant from the mean.
} 
bilateral negotiations and the less can be relied on that standard to assure an effective contract and relationship. This split is achieved using the Rauch (1999) classifications for three-digit SITC 4 commodity classes, yielding 240 separate potential bilateral flows per country pair. In a second step, those are aggregated into two export volumes, one for each group.

In the second step, the estimated exporter and importer fixed effects are each regressed on their respective preference measures $z_{i}$ and country-specific variables $\boldsymbol{C}_{\boldsymbol{i}}$ such as GDP per capita, population and internal distance:

$$
S_{i}=\alpha_{0}+\alpha_{1} \overline{\phi_{i}}+C_{i}^{\prime} \boldsymbol{\delta}+z_{i}^{\prime} \boldsymbol{\eta}+v_{i} \text { and } M_{i}=\alpha_{0}+\alpha_{1} \overline{\phi_{i}}+\boldsymbol{C}_{\boldsymbol{i}}^{\prime} \boldsymbol{\delta}+z_{\boldsymbol{i}}^{\prime} \boldsymbol{\eta}+v_{i},
$$

where $\overline{\phi_{i}}$ is the weighted average over the dyadic characteristics of each country $\overline{\phi_{i}}=\sum_{j} \boldsymbol{\phi}_{i j}^{\prime} \hat{\gamma}^{12}$

National preference leanings and bilateral differences are thus analysed separately: The parameters in the gravity equation measure only the impact of differences in preferences, a dimensionless discrepancy in outlook. Meanwhile, the fixed effects decomposition informs on the change in the willingness to trade implied by high and low national preference measures.

Extensive Margin So far, the impact of preferences has been modeled as one of repeated interactions within existing commercial relationships, that is: the intensive margin, the volume of trade flows. Yet negotiations and other communication also take place during the inception of trade, that is: the change from a zero flow to a non-zero one-the extensive margin. While it is impossible to capture the exact moment in time when a contract between firms for a country pair and specific good is first formed, an average over these events can be approximated via the number of traded goods categories. This limitation conveniently matches the GPS' own of being representative only at the country-level. Contextually, it allows insight into how the composition of trade-i.e. whether a bilateral relationship is diversified over several goods classes or restricted to only a few-is affected by preference levels of a given country or their bilateral distances.

For these purposes - and to retain coherence with the intensive margin estimatesthe extensive margin is defined as a count variable of bilateral non-zero trade flows on the three-digit SITC industry level $c: T_{i j}=\sum_{c} t_{c i j}$, with: $t_{c i j}=1$, if: $X_{c i j}>0$. $T_{i j}$ thus has a lower bound of 0 and an upper bound of 240 , the amount of threedigit industry classifications. As with its intensive margin counterpart, the extensive goods margin is estimated at the aggregate level, for differentiated and for nondifferentiated goods classes. In all cases, PPML is used in specifications otherwise identical to those for the intensive margin: ${ }^{13}$

\footnotetext{
12 The estimated coefficients for $\phi$ are chosen as weights, given their implicit information on a variable's significance. This approach also corresponds to Donaubauer et al. (2018).

13 Note that the count variable definition used in the breadth of trade extensive margin estimates is closer to an actual Poisson model than the volume speficiation.
} 


$$
T_{i j}=\exp \left(\left|z_{i}-z_{j}\right| \zeta+S_{i}+M_{j}+\phi_{i j}^{\prime} \theta\right)+v_{i j}
$$

\section{Results}

\subsection{Standard gravity}

The results from estimating the intensive margin of trade via PPML are reported in Table 3. Specification (1) is a conventional gravity equation regressing bilateral exports on distance ${ }^{14}$, contiguity, colonial relationships, existing regional trade agreements, a shared language and country fixed effects. With the exception of common language $(\operatorname{lng})$ the coefficients have the expected directions and are significant at least at the one percent level. The non-significane of common language does not change when using native and spoken language dummies. This result is in line with Melitz and Toubal (2014), who likewise find insignificant language effects when using PPML estimators ${ }^{15}$ and whose language data is used in this analysis.

Specifications (2) and (3) incorporate a bilateral distance in preferences measure similar to Jaeggi et al. (2018) or Spolaore and Wacziarg (2018) regarding values and genetics. This variable is defined as the unweighted average of the $l$ single preference distances: dpref $=\frac{1}{l} \sum_{k}^{l}\left(\mid z_{k i}-z_{k j}\right) \mid$. It measures whether preferences affect outcomes simply by being different between partners, which would speak for the overall preferences reflecting or proxying for a simple cultural (dis-)similarity. Such an outcome is not observed as dpref is non-significant in both models. Its inclusion does not alter conventional gravity parameters, implying little correlation between these variables and the preferences, given fixed effects.

In specifications (4) and (5), single preference distances across countries are included. Specification (5) also incorporates measures for distance in legal system quality leg.qlt ${ }^{16}$ and comleg, a dummy indicating whether a pair shares the same legal tradition. These are added to insure that the effect of reciprocity is not related to non-performing legal systems which might be conducive to punishing behaviour as a means to compensate for the lack of legal recourse (cf. Herrmann et al. 2008). ${ }^{17}$ This separation reveals a highly significant effect of distances in negative reciprocity

\footnotetext{
14 The measure is constructed by taking the natural logarithm of the average distance in kilometres between the most important population centre's of the two countries as calculated in Mayer and Zignago (2011).

15 Overlap with the colonial relationship dummy may partially explain these results, as both are relatively broad measures for many-faceted conditions and durations of national exposure.

16 That measure is drawn from the Worldwide Governance Indicator rule of law (in levels) using absolute differences, equivalent to the preference distance calculation.

17 Note that these parameters are significant and conducive to trade, which likely stems from the facts that navigating a system of similar design is easier and that large distances in legal quality imply the presence of one strong legal system within the pair. (The cases when both countries-or none-have a strong legal system are captured by the fixed effects.) Directions and significance also match the analysis by Yu et al. (2015), who also use WGI data as a bilateral variable.
} 
on the volume of goods exports. A one standard deviation 0.236$)^{18}$ increase-e.g. the distance between Czechia and Lithuania-, would decrease the respective trade volume by $12.5 \%$ when accounting for legal systems and $14.87 \%$ when not.

This result reflects the hypothesis that a distance in negative reciprocity might deter the less negatively reciprocal partner from engaging with a highly negatively reciprocal partner due to the latter's insistence on credible and strong punishment. These punishments - especially if unexpected-would raise the risks of a contract from the perspective of the less negatively reciprocal partner and drive him to limit his exposure to that partner. If punishment has occured already, it might motivate him to end that contract. In the same vein, the negatively reciprocal partner might execute a "grim trigger"-like strategy and thus end the relationship permanently. Regarding our hypotheses, these adverse effects appear to outmatch the potential commitment effect (or: reduced incentive to deviate) caused by a higher willingness to commit costly punishment. ${ }^{19}$

The distance in risk is also significant, albeit only at the $10 \%$ level, with an effect similar in size to that of dnegrec when accounting for legal systems. ${ }^{20}$ This corresponds to the diversification or risk transformation hypothesis, in that more riskaverse countries would outsource riskier enterprises, preferring to import their produce - and vice versa. This particular match of a more risk-averse and a risk-tolerant partner may facilitate agreement on the form of trade finance contracts because both partners could agree on allocating risk to the less risk-averse side. Given the significance and robustness issues with this result, it needs to be treated with caution.

\subsection{Differentiated and non-differentiated goods}

Expanding on the aggregated results, specification (5) of Table 3 is used for an analysis on differentiated and non-differentiated goods, according to the Rauch (1999) specifications at the 3-digit level. That separation yields two sets of comparable trade volumes and produces reasonable results for conventional variables. Most notably, distance matters significantly more for non-differentiated goods. The other conventional variables are comparable across the subsets and specifications. Legal quality continues to matter, though a common legal system appears insignificant for non-differentiated goods. The latter is likely a result of the more formalized exchanges governing non-differentiated goods trade, which reduce the importance of legal recourse. Also, as in the aggregated specification, the overall preference dimensions remain non-significant.

\footnotetext{
18 Summary statistics for the preference distances are listed in Table 7 of the Appendix.

19 In line with behavioral and managerial literature, it would have been sensible to distinguish between costly, but rational punishment and acts of revenge. Those are the forms of negative reciprocity which have been queried by sub-questions for the GPS. Unfortunately, that data has not been provided in the publicly available data set.

20 Specifically, trade increases by $14 \%$ in volume when drisk changes by one standard deviation. That deviation is 0.338 , equal the distance between Great Britain to Rwanda.
} 
In general, preferences appear to matter less for non-differentiated goods, which can likely also be attributed to the more formalized exchanges in play. Of the GPS dimensions, only bilateral distances in negative reciprocity matter for non-differentiated goods and their significance is also diminished compared to the aggregate or the differentiated cases. For differentiated goods, the results for bilateral distances in negative reciprocity remain similar to the aggregated results. ${ }^{21}$

Distance in risk is still significant at the $10 \%$-level only, but solely for differentiated goods. This fits the risk transformation hypothesis as transformation can only occur with different risk profiles. If risk-averse players self-select into the less volatile differentiated goods, their export markets must be less risk-averse, or else they would have the same production profile. On the other hand, more risk-tolerant players benefit from trading with more risk-averse partners willing to pay a premium for the risk avoidance. Hence, the effect is positive. Secondly, non-differentiated goods can be traded on exchanges, thus reducing the options for less risk-averse players to strike direct bilateral agreements for risk transformation purposes ${ }^{22}$.

Distances between countries in positive reciprocity have a weakly significant, positive effect on trade volumes for differentiated goods (specification (2) of Table 4 in the Appendix), whereas there is no significant effect for non-differentiated goods. The coefficient corresponds to a $9.2 \%$ increase in trade per standard deviation $(0.31$; equal the distance between Austria and the Netherlands). This positive effect, if robust, likely reflects the stabilising effect of rewards by the more positively reciprocal player towards his partner, for whom this behaviour would be unexpected given his different reciprocity profile, but beneficial. In this dimension, cultural distance appears to have a positive effect on the intensity of trade. This further highlights why the overall distance in preferences is not significant and presents a case wherein contrasting values or preferences might be beneficial to economic exchange.

\footnotetext{
21 Interestingly, this relationship becomes more nuanced when considering OLS and alternative PPML estimations of the gravity specification. A summary of these is displayed in Tables 10, 11 and 12 in the Appendix. In an OLS setting, the coefficient for dnegrec loses significance and even becomes positive for differentiated goods. It becomes significant and negative again when weighting the observations with their level trade flows and remains negative for all alternative PPML estimations. The divergence between methods notably subsides for the OECD subset (see Table 21 in the Appendix), which has both less zeroes ( $1 \%$ to $6.5 \%$ in the full set) and a higher concentration of larger flows. The OLS results are also sensitive to the treatment of zero flows, providing different (non-)significances depending on the implementation.

These results hint at a non-linearity of the relationship in line with the hypothesis that high levels of negative reciprocity might enable a trading partner to overcome the obstacles of weak legal institutions. Hence the positive effect in OLS. For larger trade flows, this effect would decline, yielding instead a negative relationship due to the punishment risk. Additionally, countries with larger trade flows are typically economically more powerful and tend to have stronger institutions (or be involved with third-party mediators). In our sample, GDP and the legal quality indicator (leg.qlt) share a correlation of about 30\%, while trade volumes are correlated by around $10 \%$ with the legal quality indicators for each country in the pair. Further investigation of this link would be interesting, but is beyond the explorative scope of this paper.

${ }^{22}$ For which they would not have the same valuation as risk-averse players anyway, given their higher risk tolerance.
} 


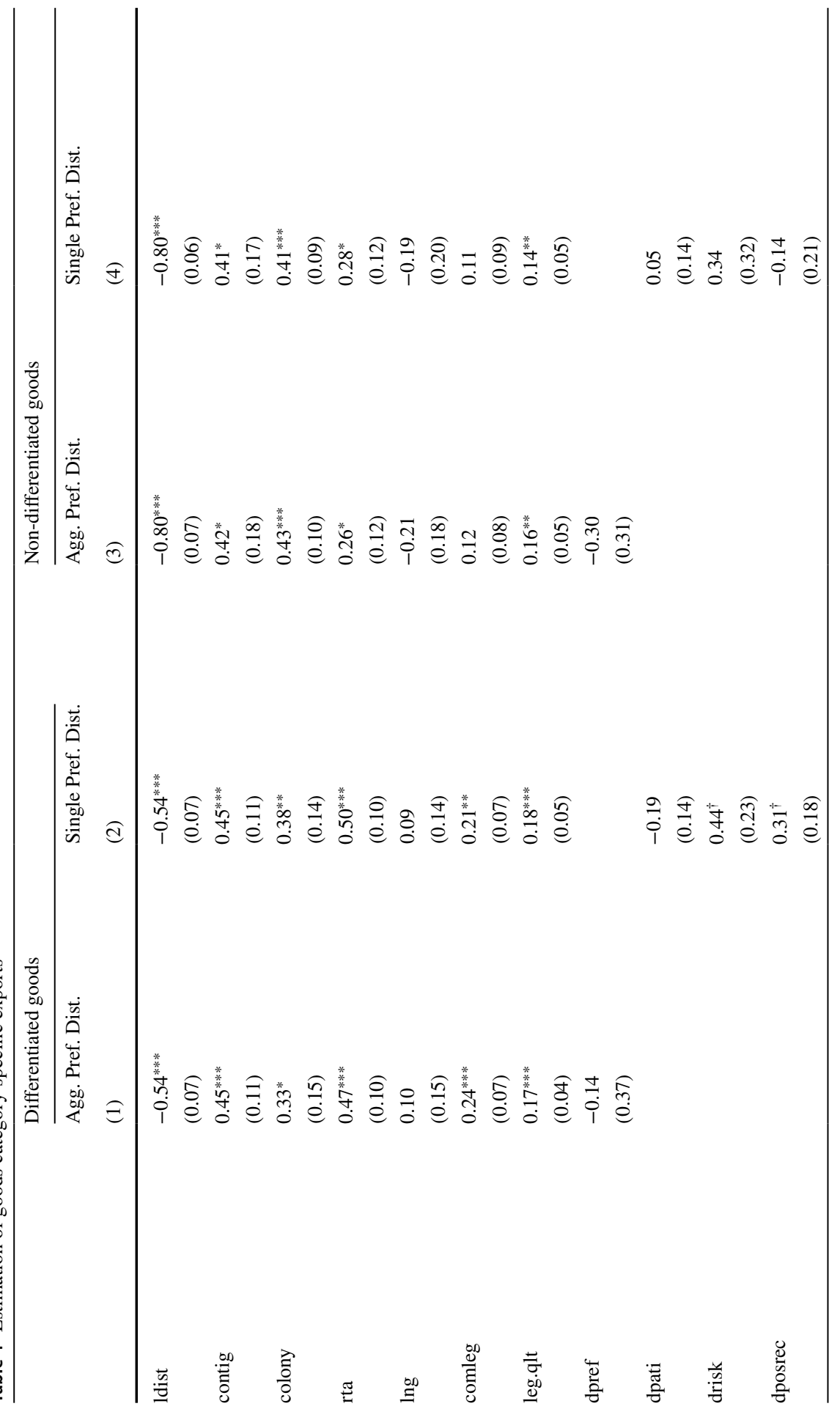




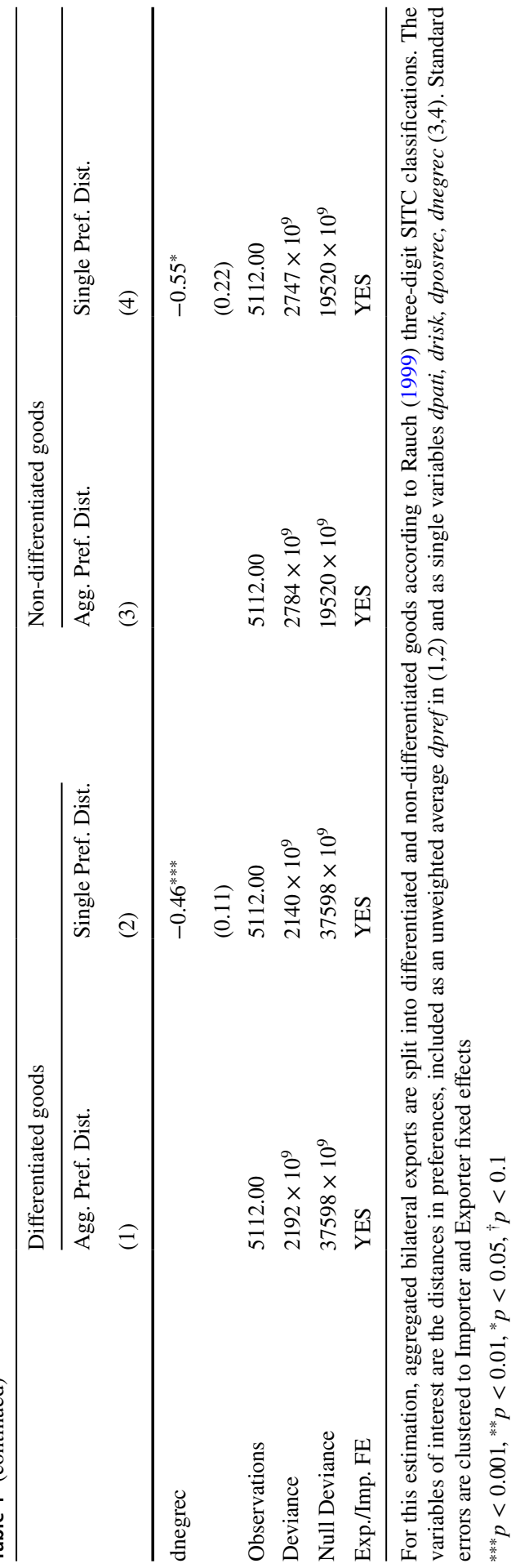




\subsection{Impact on average barriers}

The fixed effects, i.e. the average trade barriers, are extracted from the single preference specifications (2) and (4) of Sect. 5.2, Table 4, to decompose the effects of GPS preferences on trade outcomes. The effects from the separate sets are used due to the substantial observed differences in coefficients between the goods classes. ${ }^{23}$ Exporter and importer fixed effects of the two goods specifications are each regressed on average bilateral characteristics relating to the country in question, population and per-capita GDP, a landlocked dummy and the single preferences in their levels. Population pop and per-capita GDP gdpcap are significant and have the expected positive signs for importers and exporters alike. Being landlocked has an expected negative effect, signalling the higher transport costs arising from lacking ocean access. Average bilateral characteristics are included for consistency in accordance with Head and Mayer (2014) only and cannot be interpreted on their own. The results are shown in Table 5.

As mentioned in Sect. 3, it is usually the exporter who faces a delay in payment and the risk of default due to the prevalence of open account (OA) payment forms. ${ }^{24}$ Indeed, our results suggest that preferences only seem to matter for exporters-displayed in specifications (1) \& (3). ${ }^{25}$

Reasonably then, risk-taking is also the dominant preference. The more risk-averse a population is on average ${ }^{26}$, the more differentiated goods it exports but also the less non-differentiated ones. However, the effect on differentiated goods is stronger. For differentiated goods, a one standard deviation change in risk-taking (0.302) would lower the average fixed effect (21.7) by 3.35\%. This corresponds to a decrease in exports of approximately equal size and a jump from Brazil's risk attitude to Sweden's. The same change implies an increase of $2.28 \%$ for non-differentiated goods. ${ }^{27}$

According to these results, higher risk-aversion implies a comparative advantage for and correspondingly a product mix heavy in differentiated goods, whereas a higher risk tolerance yields a product mix intensive in non-differentiated goods. This corroborates the risk transformation argument for distance in risk as alternative suppliers for differentiated goods are scarcer, increasing the bargaining power of the exporter even in an Open Account setting. Given this incentive, risk-averse suppliers would self-select into these goods.

\footnotetext{
${ }^{23}$ Second stage estimations for the aggregate bilateral volumes have also been computed, but found to be non-significant, which is understandable given the effect directions observed in Table 5 .

${ }^{24}$ As nicely summarised by Niepmann and Schmidt-Eisenlohr (2017), all common contract forms except for cash-in-advance (CIA) place a risk and financing burden on the exporter.

${ }^{25}$ It must be noted, however, that PPML tends to overstate origin country fixed effects, which might also contribute to the non-significance of the parameters of interest in the second-stage regression for the importer. When estimating the first stage with OLS instead of PPML, the second stage results remain similar for differentiated goods, but patience and risk become non-significant for non-differentiated goods.

${ }^{26}$ The variables are normalized to the global average in the GPS data. That mean is risk-averse, not riskneutral.

${ }^{27}$ Given these opposing effects for the two commodity class subsets, it is unsurprising that the preferences would have no significant impact on the fixed effects of total bilateral flows.
} 
Table 5 Estimation of fixed effects composition

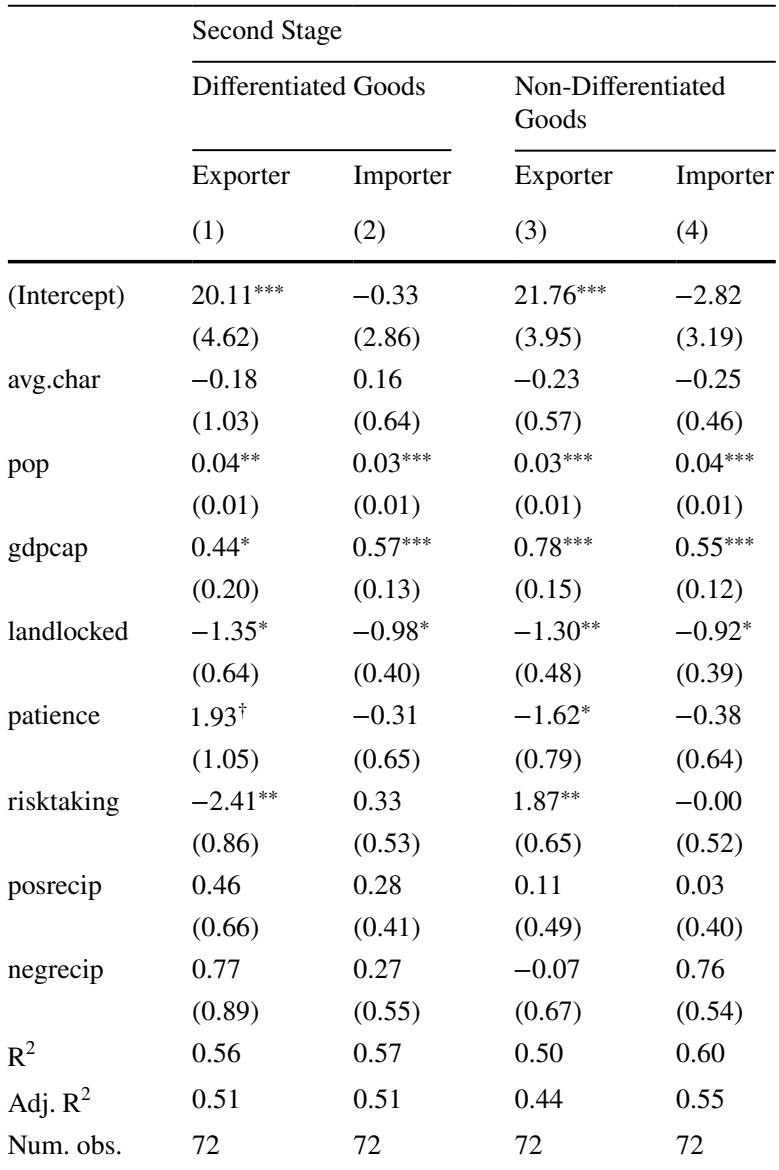

The Fixed Effects represent Average Trade Barriers and are estimated via a two-step approach. Exporter and importer fixed effects are extracted from Table 4 specifications (2) and (4) and estimated via OLS using unilateral size and location variables, the average bilateral characteristics relating to the country in question and the single preference variables. Columns (1) and (2) show country characteristics for differentiated goods and (3) and (4) for non-differentiated goods. Exporter results are displayed first in each case. Classical standard errors are provided, since robust standard errors are functionally identical

${ }^{* * *} p<0.001,{ }^{* *} p<0.01,{ }^{*} p<0.05,{ }^{\dagger} p<0.1$

Meanwhile, more risk-tolerant players gain a comparative advantage for non-differentiated goods as they put less weight on the associated opportunity costs - i.e. the risk of being substituted with a competitor and the general OA risks. As they are effectively offered risk premia for providing non-differentiated goods, risk-tolerant players will conversely self-select into these. However, the formal organization 
of the markets for non-differentiated goods and nation-specific resource allotments should reduce the effect on these goods categories. ${ }^{28}$

Patience yields opposite results to risk: a one standard deviation increase $(0.370$ : from Brazil to Vietnam) in the preference increases exports of differentiated goods by $3.28 \%$, but decreases those of non-differentiated ones by $2.42 \%$. That is, more patient countries export more in differentiated goods and less in non-differentiated ones. These coefficients align with their underlying long-term considerations or discount factor arguments. Differentiated goods require more up-front investment to produce or trade and involve more complex searches and negotiations with potential partners. Both requires a longer time horizon for the players in question, while non-differentiated goods remove the necessity for search and negotiations by accessing organized exchanges.

Additionally, different national patience levels allow for term transformation, i.e. firms specializing on products maximizing profits corresponding to their country's particular time horizons. These foci would differ between nations, constituting competitive advantages and efficiency gains from trade, subsequently reinforcing these specializations. Notably, due to these specializations becoming more niche, gains could be achieved even between partners of similarly high time preferences, thus explaining the non-significance of dpati.

Capital allotment-based on discount and interest rates-and contract enforcement would appear as reasonable channels for these specialization procedures. ${ }^{29}$ As illustrated by Nunn (2007), better enforcement implies more trade in goods which are intensive in relationship-specific investments. Patience, as long-term orientation, would be conducive to considering gains from repeated interactions and more elaborate trade networks. The costs for contract enforcement and its design would then become bearable given the expected future gains from engaging in the effort.

Lastly, the change in effect directions for differentiated and non-differentiated goods further underlines that term and risk preferences address more than cultural heterogeneity when it comes to trade. These results also explain the lack of a clear relationship between aggregated, normalized exports and national preferences in Fig. 1.

\subsection{Breadth of trade: the extensive margin}

Lastly, the extensive goods margin of trade and thus the negotiations establishing economic exchange are observed using the 3-digit SITC-industry specifications to transform trade volumes into 240 binary choices per country pair. That is: Does country $i$ export good $c$ to country $j$ ? Specification (1) of Table 6 presents a conventional PPML gravity estimation for the aggregation of these choices. Specification (2) displays the extensive margin equivalent to Sect. 5.1, while specifications (3) and (4) are equivalent to Sect. 5.2. The coefficients and significances for the

\footnotetext{
${ }^{28}$ It is beyond the scope of this paper to analyse potentially biasing influences of nation-specific resource allotments on trade outcomes.

29 The latter is especially notable as inclusion of a legal quality variable causes patience to become insignificant. The corresponding results are displayed in Table 13 in the Appendix.
} 


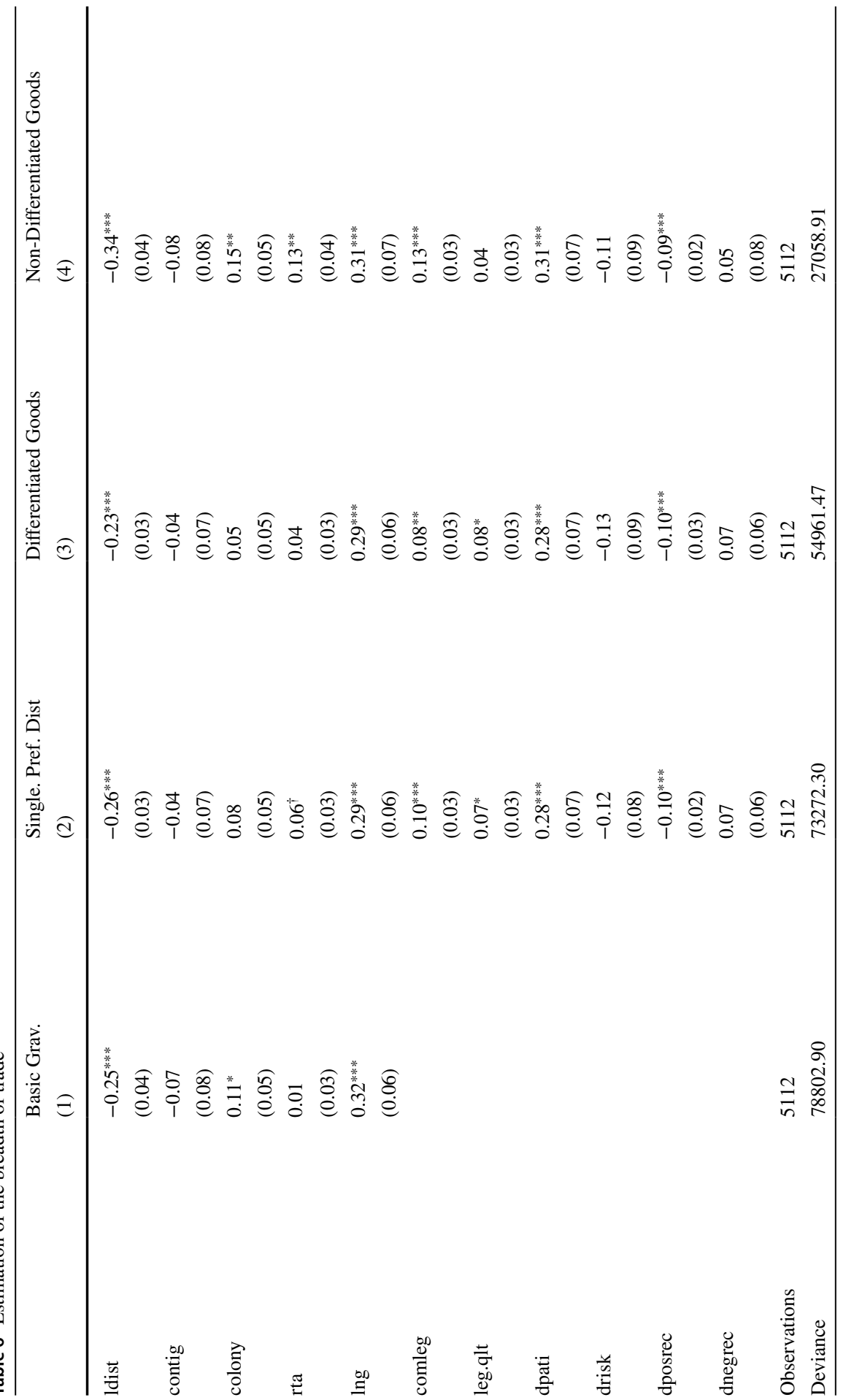




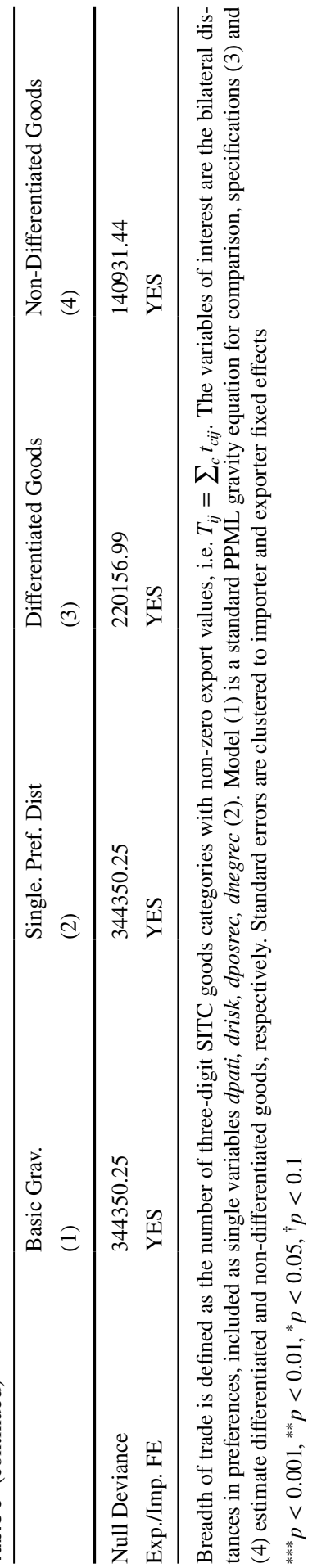


conventional variables are reasonable and in line with the volume results, except for the (partial) non-significance of contiguity and regional trade agreements. ${ }^{30}$

Distance in patience is significant for the breadth of trade between two nations. ${ }^{31}$ A one standard deviation increase in dpati (0.331, Estonia to France) increases the number of goods categories traded by 9 to $10 \%$. This positive effect supports the term transformation and specialization argument. Likely, the more patient country in a respective pair invests more heavily in his trade network to achieve further specialization gains. If so, country pairs with higher bilateral distances in patience would follow diverging specialization and investment paths, yielding different product sets and thus venues for trade across goods classes. ${ }^{3233}$ This interpretation also aligns with the observation that high patience reduces (outward) export barriers for differentiated goods, while low patience appears to reduce them for non-differentiated commodities (see Sect. 5.3). Term orientation can therefore be seen as a motivation for specialization and trade.

Distances between countries in positive reciprocity also appear to affect the number of goods categories traded. Per standard deviation of distance (France and Spain, for example), the number of categories traded is reduced by $3 \%$. This adverse effect is puzzling. Given the contract-stabilising effect of unexpected rewards to cooperative behaviour by one party, which would intensify existing relationships but not affect the development of new ones, a non-significant coefficient had been expected. Similar to that argument, the non-significance of dnegrec implies that its negative effect on trade volumes is not based on the threat of punishment, but reduction of exposure in existing contracts. ${ }^{34}$

\footnotetext{
${ }^{30}$ Elaborating on these effects, commonality of language (lng) is significant in these PPML classifications, implying that the issue of their non-significance in the volume specifications might be related to that dependent variable. A common language might simply be more relevant for establishing trade than for intensifying it. As for contiguity, its non-significance and negative coefficient might point to geographic clusters of countries with similar profiles. The partial non-significance for real trade agreements appears related to the presence of legal control variables, which could imply that trade agreements are not effective without legal enforcement. Furthermore, it is not readily apparent why bilateral trade arrangements would expand the amount of goods categories traded. Both partners in negotiations would attempt to improve the terms of trade for their strengths, their specializations and not seek to expand trade into goods categories where neither is specialized or even active.

${ }^{31}$ In the second stage for the breadth of trade specification, patience levels are not significant. Risk remains significant and its coefficient positive, but only for exporters of differentiated goods (see Table 15 in the Appendix).

${ }^{32}$ Note that this also relates to the non-significance of dpati in the volume specifications. Due to the increasing specialization, two players of high long-term orientation could still trade goods within categories to their mutual benefit. Thus, their trade need not be smaller in volume than that between players of different patience levels. On the extensive margin, however, opportunities arise from high and diverging specialization. This can be observed in the raw data, albeit influenced by the correlation between GDP and patience. In the full set, pairs with one highly patient partner trade in twice as many goods categories and around five times the volume as pairs where both partners have low patience. Pairs of two highly patient partners, however, trade in 50\% more categories than those with one highly patient partner and, again, around five times the volume.

${ }^{33}$ dpati is agnostic to the direction of the distance and does not capture whether the exporter's or the importer's level is higher. However, a dummy variable capturing this information is neither significant nor does it alter results.
}

${ }^{34}$ Alternatively, a severe punishment could terminate the trade flow, in which case these events would not register in the static extensive margin estimation used here. 


\section{Robustness}

This section addresses three potential robustness issues: potential sampling issues, the definition of the preference variables and the relationship to surveys similar to the GPS.

\subsection{OECD subset}

As mentioned before, economic preferences - and the experiments and questions by which they are measured-might be influenced by the economic situations of the subjects in question. Risk and patience specifically might be linked to the wealth and development path of the country in question beyond relationships covered by GDP per capita or institutional settings. If preferences are linked to economic characteristics, endogeneity could ensue through relationships between them and trade patterns and intensities. To control for this, a subset of all OECD countries also included in the GPS is used. The greater similarity of OECD countries in terms of wealth, institutional quality and societal organisation mitigates the endogeneity risks. ${ }^{35}$ On the other hand, it also limits generality of results due to the smaller set of 25 members and in the case that preference distances between countries impact trade differently for less developed nations. ${ }^{36}$

Comparing the gravity estimations for GPS and OECD countries, preference distances have stronger effects within the OECD than for the full GPS set-see Tables 18 and 19 in the Appendix for detailed results. Overall, the results also imply that preferences might matter more in situations where other issues such as strong discrepancies in economic development or the legal systems of the country pair are less relevant. The smaller effects for commonalities in the legal systems and the negative, but barely significant effects of differences in the quality of legal systems support this interpretation.

\subsection{Alternative preference definitions}

In addition to the unilateral preference levels and absolute distances between countries used in the main analysis, two alternative specifications have been tested: squared preference distances between countries and maximum preference values per pair. The results for the corresponding gravity equations, applied to goods category-specific exports, are displayed in Tables 22 and 23 of the Appendix. In the

\footnotetext{
35 As well as a resulting focus on western nations.

36 The generality of the OECD robustness check is restricted further by the GPS' definition. As the distributions are normalized to the individual level of the full set, preferences in the OECD set need not follow that same normal distribution. They cannot be computed in the same manner either because nonnormalized data is not provided by the GPS. Additionally, the distribution of national preferences and their bilateral distances is significantly different within the OECD set compared to the whole GPS set, see Tables 16 and 17 of the Appendix.
} 
former case, the effects for bilateral distances in negative reciprocity remain similar, while distances in patience and positive reciprocity become significant (at higher confidence levels). Neither effect changes directions. These additional significances might be a venue for future research in that they could imply a non-linearity in the effect of distances.

In the maximum value cases, negative reciprocity is highly significant. ${ }^{37}$ Risk and positive reciprocity remain significant at the $10 \%$-level for differentiated goods. For negative reciprocity, a higher maximum value is associated with a decrease in trading volume. That is, the larger the distance, the smaller the trade volume, which is equivalent to the results from the main analysis. For risk and positive reciprocity, higher maximum values increase trading volumes. This likewise fits the overall positive effect for distances observed in the main analysis, thus supporting the risk transformation and negotiation mechanisms. Given the greater difficulty with disentangling effects, this specification is not used in the main analysis. ${ }^{38}$

\subsection{Relationship with similar surveys}

While the GPS is unique in its combination of decision-relevant preferences and experimental validation, some of its contents have been analysed before. The World Values Survey (WVS) (Jaeggi et al. 2018) and the Hofstede Dimensions (Hofstede et al. 2010) report measures for some of the GPS preferences, which are used for robustness checks in this analysis. Additionally, Wacziarg's genetic and religious distances (Spolaore and Wacziarg 2016, 2018) are used to ascertain their relationship with preferences, controlling for potential links between these traits and preferences. This follows the literature on ancient origins of cultural and societal traits.

World Values Survey The World Values Survey (WVS) is a global study designed to gather information on values and beliefs of different nations. It is a questionnaire containing items relating to the subject's personal and professional life, their beliefs, culture and values, as well as questions on the perceptions of their society. The evaluation includes risk and time preferences, allowing direct comparison with the GPS. 57 countries of the GPS are also included in the WVS, 47 of them contain all of the items, providing a sufficiently large set for comparison on aggregate volumes. Bilateral distances for the WVS variables are drawn from Jaeggi et al. (2018).

The output table can be found in the Appendix as Table 24. Using mean distance in World Values Survey items instead of the aggregated distance in GPS preferences does not alter the result noted in Sect. 5.1. Both coefficients are non-significant. When replacing risk and time preferences with their WVS equivalents, WVS time

\footnotetext{
37 Results are identical for minimum preference values, but with flipped signs.

38 The minimum/maximum specifications were also estimated using a dummy approach. Therein, a maximum (minimum) pair preference value is classified as 1 when its value is one standard deviation above (below) the average preference value and 0 otherwise. Using this approach, negative reciprocity extreme values remain significant, while risk and reciprocity lose theirs. Interestingly, patience becomes significant at the $10 \%$ level in this approach, with an effect composition similar to negative reciprocity. However, this approach is only suited for analysing extreme distances and thus not useful for the main analysis, but further underlines the robustness of the effect for negative reciprocity.
} 
preferences become significant at the 5\% level. Risk does not, negative reciprocity remains significant. The discrepancy in risk and time preference significance might result from the reduced sample size, if the reduction is non-random. Depending on a person's (or nation's) material wealth, saving becomes easier and risk-aversion more logical given higher potential losses. This bias might also manifest differently depending on the phrasing of questions or the execution of experiments.

Hofstede Dimensions Geert Hofstede has modelled national culture as a six-dimensional model with the dimensions proposed as basic issues for societal organisation. These dimensions include long-term orientation and uncertainty avoidance, which correspond to patience and risk attitude in the GPS. Due to Hofstede's calculation, only level effects can be analysed. For that purpose, first stage gravity equation without preference distances is estimated to avoid confounding. ${ }^{39}$ The fixed effects of that estimation are analysed using the same specification as in Sect. 5.3, but with the Hofstede measures for patience and risk (see Table 25 of the Appendix). Of these, only patience is significant, while risk is not. However, the Hofstede sample encompasses only 44 countries instead of the GPS' 72 and its indices are defined much more broadly in terms of values, morale and philosophy, further limiting their accuracy and comparability.

Genetic and Religious Distance Thirdly, the relationship between preferences and other persistent, long-term drivers of cultural characteristics has to be considered, specifically: common origins. To this end, measures for genetic and religious distance from Jaeggi et al. (2018) are used. Both aspects can be seen as persistent influences on developing characteristics of any nation's population and their distance relates to the (in-)frequency of interaction between any two nations. If not the causes, they can still be used as proxies for shared history or origins. Table 26 of the Appendix shows the detailed results for weighted distances and an alternative definition of these distances using only the dominant genetic or religious "group" within each country. Neither measure affects coefficients or significance of GPS variables.

\section{Conclusion}

This analysis suggests that behavioural leanings can express themselves in trade outcomes and outlines mechanisms - term and risk optimisation on one hand and negotiation on the other-by which these outcomes manifest. In contrast to cultural distances, this relationship is not constrained to differences reducing trade. The effects of this mechanism are more pronounced and more robust for differentiated goods, which is reassuring as these goods are more negotiation- and specialisation-heavy than standardised or exchange-traded goods. They are also centered on the exporter, which aligns well with the prevalence of open account in trade finance, placing the risk primarily with the exporter.

Term and risk preferences appear to impact trade outcomes through transformation mechanisms. That is, investment, production and trade patterns are subject to different

\footnotetext{
${ }^{39}$ Doing so does not alter the results for patience and risktaking, stressing that preference levels and distances are distinct effects.
} 
risks and amortization cycles. This prompts players to self-select into products suiting their own preferences in these matters, if given the chance-which can be provided by trade. These selections then lead to specializations, providing comparative and competitive advantage as well as further opportunity for trade. Consequently, countries with populations leaning towards risk-aversion and patience export more differentiated goods. This is reflective of the higher effort associated with establishing their production and the greater difficulty, for their partner, to change suppliers. Moreover, distances between countries in patience correspond to trading in more product categories, reflecting the growth in trading opportunities between differently specialized partners.

For reciprocity, the mechanisms depend not on preference leanings, but on bilateral differences. Distances between countries in negative reciprocity in particular adversely impact trade volumes. This supports the dual hypothesis that the punishment costs and risks associated with a more negatively reciprocal partner coerce a less negatively reciprocal partner towards limiting his exposure. Conversely, distances between countries in positive reciprocity weakly intensify trade relationships. Unexpected rewards or gifts for cooperative behaviour by the more positively reciprocal player would be appreciated by their partner, strengthening the relationship.

While we cannot speak of causal inference, term, risk and reciprocity attitudes present an intriguing approach towards explaining certain anomalies in trade flows and behaviours not covered by conventional theory. This approach joins the literature strands on trade, behavioural economics and contracts with one another, tying trade outcomes to the people deciding upon their design. At this intersection and following from our analysis, further research questions unfold, of which we want to address a few.

One question is that of the relationship between preferences and the duration of trade. Patience and positive reciprocity might well contribute to more persistent relationships, which could perhaps be investigated using a long-term panel of bilateral trade intensity. Risk and negative reciprocity, on the other hand, could diminish that persistence. Another question would be whether and how term and risk considerations would affect more disaggregated trade flows, since our results and specialization channel would postulate high and highly specific flows.

More technically, we have found signs for a potential non-linearity in the relationships between trade activity and preferences. Above a presumed threshold, the impact of national preferences and their bilateral distances might change, as is hinted at by the results for the OECD subset. For negative reciprocity, there are signs for a non-linearity relating not to the preferences but to the trade volume in question. Both of these anomalies could be interesting for further studies. At the same time, a decomposition of negative reciprocity into its different levels of manifestation-i.e. costly, but rational punishment vs. irrational revenge-would be interesting.

Lastly, we want to address policy implications. Preferences might define limits to the effects of infrastructure, institutions and political action, including trade agreements, on economic outcomes. At the same time, term and risk transformation could add another dimension to trade negotiations and the perspectives for judging their outcomes, as they provide a potential source for gains from trade. With regards to negative reciprocity and the risk of punishment, supranational mediators for trade disputes might be able to alleviate concerns of both sides by delegating punishment to a neutral and transparent court, increasing predictability of the process. 


\section{Appendices}

\section{Export substitutes for import data}

Eight countries had not reported any data by the time the data was downloaded. These missing entries were replaced with existing export data by their reporting partner nations. This method is potentially biased due to the complete lack of data on trade between these eight countries and potential reporting errors with regards to the traded volumes. While the former issue cannot be addressed with the data available, the latter issue can be investigated by comparing export and import flows of all countries within the GPS set that do report their foreign trade. For these countries, average exports and imports to all other reporting countries in the set are computed as well as standard deviations for these flows. The two resulting distributions can then be tested against the null hypothesis of being drawn from the same population by conducting Kolmogorov-Smirnov tests. That null hypothesis cannot be dismissed for the two- or either one-sided test. Given these results, the export data can thus be used as replacement for imports of non-reporting countries.

For robustness, all estimates have also been conducted for a subset including reporting countries only. In these estimations, all effects grow in significance and size in the extensive margins. At the intensive margin, patience and its distance become less pronounced or even non-significant, while the effect of risk becomes slightly stronger, both for distances between countries and levels of a given country.

\section{On the exclusion of altruism and trust}

In the GPS, altruim is defined as the willingness to contribute to good causes or give to others, while trust is defined more broadly as the belief in other people's good intentions. Unfortunately, the definitions for these two variables as used in the GPS are too general for use in the context of this paper.

Trust is measured by the participants' level of agreement to the statement $I$ assume that people have only the best intentions (see Falk et al. 2018), which does not reflect managerial intent. Even if both sides in a negotiation had the best intentions, they still represent different interests. More importantly, the measure does not consider specific national or bilateral biases, which might overrule a person's general outlook; indeed, previous research into the role of trust for trade specifically investigates such bilateral perceptions of trustworthiness (e.g. see Yu et al. 2015).

Altruism, measured by the willingness to donate to good causes ${ }^{40}$, likewise does not reflect the situation faced by a negotiator. Hence, both measures are excluded from the main analysis, but assessed in the robustness section (Tables 13, 14).

\footnotetext{
40 The willingness is assessed by a question directly inquiring the willingness to donate without expecting a return and by the reply to a hypothetical question on how much one would donate, if given a 1000 Euro.
} 
Table 7 Summary statistics for distances in preferences

\begin{tabular}{lllllll}
\hline Statistic & Mean & St. Dev. & Min & Max & Top 2 & Bottom 2 \\
\hline dpati & 0.415 & 0.331 & 0.0001 & 1.684 & NIC-SWE, RWA-SWE & ITA-JPN, IND-PER \\
drisk & 0.338 & 0.273 & 0.0001 & 1.763 & PRT-ZAF, NIC-ZAF & GTM-UKR, ISR-KEN \\
dposrec & 0.382 & 0.298 & 0.0005 & 1.608 & EGY-MEX, GEO-MEX & CRI-IDN, POL-ZWE \\
dnegrec & 0.309 & 0.236 & 0.00002 & 1.228 & GTM-HRV, HRV-MAR & BRA-KAZ, ARG-VNM \\
dpref & 0.358 & 0.124 & 0.061 & 0.812 & GEO-SAU, EGY,ZAF & AUS-CAN, AUT-CHE \\
\hline
\end{tabular}

Table 8 Summary statistics for trade on goods category level

\begin{tabular}{llllll}
\hline Statistic & $\mathrm{N}$ & Mean & St. Dev. & Min & Max \\
\hline Trading & $1,261,440$ & 0.360 & 0.480 & 0 & 1 \\
Volume & $1,261,440$ & $8,935,006.000$ & $228,039,017.000$ & 0 & $74,214,173,234$ \\
\hline
\end{tabular}

Trading is a dummy variable which takes value 1 when a specific goods category is traded between a given country pair and 0 otherwise. Volume is the volume exported from one country to a specific partner country. For each variable, key distributional statistics are provided

Table 9 Summary statistics for bilateral trade outcomes

\begin{tabular}{llllll}
\hline Statistic & N & Mean & St. Dev. & Min & Max \\
\hline Volume (in mio.\$) & 5256 & 2144.40 & $11,944,18$ & 0 & $425,430.22$ \\
Trade Links & 5256 & 86.317 & 71.344 & 0 & 224 \\
Avg. Exp. Partner & 5256 & 67.342 & 5.756 & 47 & 72 \\
Avg. Imp. Partner & 5256 & 67.342 & 5.990 & 48 & 72 \\
\hline
\end{tabular}

Volume is the average value of goods exported from country $i$ to country $j$ for all countries in the set. Trade Links is the average number of goods exported from $i$ to $j$, again for all country pairs. Avg. Exp. Partner and Avg. Imp. Partner denote the average number of partners for a given exporter and importer, respectively 
Table 10 Alternative estimators for aggregated bilateral exports

\begin{tabular}{|c|c|c|c|c|c|c|}
\hline \multirow{3}{*}{$\begin{array}{l}\text { Estimator } \\
\text { Sample }\end{array}$} & OLS & PPML & PPML & $\begin{array}{l}\text { OLS } \\
\text { (weighted) }\end{array}$ & $\begin{array}{l}\text { PPML } \\
\text { (share) }\end{array}$ & \multirow{3}{*}{$\begin{array}{l}\text { PPML } \\
\text { (share) } \\
\text { flow }>0 \\
\text { (6) }\end{array}$} \\
\hline & \multicolumn{2}{|l|}{ flow $>0$} & flow $>0$ & \multicolumn{2}{|l|}{ flow $>0$} & \\
\hline & (1) & (2) & (3) & (4) & (5) & \\
\hline \multirow[t]{2}{*}{ ldist } & $-1.26^{* * *}$ & $-0.59^{* * *}$ & $-0.62^{* * *}$ & $-0.61^{* * *}$ & $-0.86^{* * *}$ & $-0.88^{* * *}$ \\
\hline & $(0.05)$ & $(0.06)$ & $(0.06)$ & $(0.03)$ & $(0.08)$ & $(0.08)$ \\
\hline \multirow[t]{2}{*}{ contig } & $0.42^{* *}$ & $0.48^{* * *}$ & $0.41^{* *}$ & $0.65^{* * *}$ & $0.27^{\dagger}$ & $0.25^{\dagger}$ \\
\hline & $(0.16)$ & $(0.14)$ & $(0.14)$ & $(0.06)$ & $(0.14)$ & $(0.14)$ \\
\hline \multirow[t]{2}{*}{ colony } & 0.21 & $0.33^{* *}$ & $0.28^{* *}$ & $0.50^{* * *}$ & $0.44^{* * *}$ & $0.40^{* *}$ \\
\hline & $(0.17)$ & $(0.10)$ & $(0.09)$ & $(0.09)$ & $(0.13)$ & $(0.13)$ \\
\hline \multirow[t]{2}{*}{ rta } & $0.22^{* *}$ & $0.35^{* * *}$ & $0.35^{* * *}$ & $0.66^{* * *}$ & $0.36^{* * *}$ & $0.36^{* * *}$ \\
\hline & $(0.07)$ & $(0.09)$ & $(0.09)$ & $(0.06)$ & $(0.09)$ & $(0.09)$ \\
\hline \multirow[t]{2}{*}{$\operatorname{lng}$} & $0.85^{* * *}$ & -0.06 & -0.11 & 0.08 & 0.25 & 0.20 \\
\hline & $(0.11)$ & $(0.13)$ & $(0.12)$ & (0.09) & $(0.15)$ & $(0.15)$ \\
\hline \multirow[t]{2}{*}{ comleg } & $0.41^{* * *}$ & $0.15^{*}$ & $0.16^{*}$ & $0.19^{* *}$ & $0.29^{* * *}$ & $0.29^{* * *}$ \\
\hline & $(0.07)$ & $(0.07)$ & $(0.08)$ & $(0.06)$ & $(0.07)$ & $(0.07)$ \\
\hline \multirow[t]{2}{*}{ leg.qlt } & $0.30^{* * *}$ & $0.15^{* * *}$ & $0.14^{* * *}$ & $0.18^{* * *}$ & 0.05 & 0.04 \\
\hline & $(0.04)$ & $(0.03)$ & $(0.03)$ & $(0.02)$ & $(0.04)$ & $(0.04)$ \\
\hline \multirow[t]{2}{*}{ dpati } & 0.16 & -0.16 & -0.16 & $0.72^{* * *}$ & 0.07 & 0.05 \\
\hline & $(0.12)$ & $(0.10)$ & $(0.10)$ & $(0.06)$ & $(0.13)$ & $(0.13)$ \\
\hline \multirow[t]{2}{*}{ drisk } & $0.61^{* * *}$ & $0.52^{\dagger}$ & $0.50^{\dagger}$ & $1.38^{* * * *}$ & 0.01 & -0.02 \\
\hline & $(0.15)$ & $(0.28)$ & $(0.28)$ & $(0.18)$ & $(0.33)$ & $(0.32)$ \\
\hline \multirow[t]{2}{*}{ dposrec } & -0.15 & -0.04 & -0.05 & 0.10 & -0.11 & -0.10 \\
\hline & $(0.12)$ & $(0.18)$ & $(0.17)$ & $(0.10)$ & $(0.11)$ & $(0.11)$ \\
\hline \multirow[t]{2}{*}{ dnegrec } & -0.12 & $-0.53^{* *}$ & $-0.55^{* *}$ & $-1.19^{* * *}$ & -0.13 & -0.14 \\
\hline & $(0.15)$ & $(0.16)$ & $(0.17)$ & $(0.12)$ & $(0.13)$ & $(0.13)$ \\
\hline Observations & 4821 & 5112 & 4821 & 4821 & 5112 & 4821 \\
\hline Deviance & & $4562 \times 10^{9}$ & $4253 \times 10^{9}$ & & 44.64 & 42.01 \\
\hline Null Deviance & & $52347 \times 10^{9}$ & $51028 \times 10^{9}$ & & 224.63 & 216.19 \\
\hline $\mathrm{R}^{2}$ & 0.27 & & & 0.20 & & \\
\hline $\operatorname{Adj} . R^{2}$ & 0.25 & & & 0.17 & & \\
\hline Exp./Imp. FE & YES & YES & YES & YES & YES & YES \\
\hline
\end{tabular}

All estimations are based on model (5) of Table 3, i.e. the PPML estimation of single preference distances with legal quality as control variable. These results are also displayed in column (2) of this table. Standard errors are clustered to Importer and Exporter fixed effects, identical to that model.

The alternative estimators follow Mayer et al. (2019), specifically their Table 3, in controlling for potential confounding effects of both large and zero trade flows. Column (1) provides the OLS equivalent of the PPML main equation, with zero flows excluded. Column (3) provides the same estimation, but via PPML. In column (4), the model is estimated with weighted least squares; level trade flows are used as weights. Columns (5) and (6) estimate the main PPML model with trade shares, i.e. bilateral imports divided by total imports of that importer, as dependent variable

${ }^{* * *} p<0.001,{ }^{* *} p<0.01,{ }^{*} p<0.05,{ }^{\dagger} p<0.1$ 
Table 11 Alternative estimators for bilateral exports in differentiated goods

\begin{tabular}{|c|c|c|c|c|c|c|}
\hline \multirow{3}{*}{$\begin{array}{l}\text { Estimator } \\
\text { Sample }\end{array}$} & OLS & PPML & PPML & $\begin{array}{l}\text { OLS } \\
\text { (weighted) }\end{array}$ & $\begin{array}{l}\text { PPML } \\
\text { (share) }\end{array}$ & \multirow{3}{*}{$\begin{array}{l}\text { PPML } \\
\text { (share) } \\
\text { flow }>0 \\
(6)\end{array}$} \\
\hline & \multicolumn{2}{|l|}{ flow $>0$} & flow $>0$ & \multicolumn{2}{|l|}{ flow $>0$} & \\
\hline & (1) & (2) & (3) & (4) & (5) & \\
\hline \multirow[t]{2}{*}{ ldist } & $-1.36^{* * *}$ & $-0.54^{* * *}$ & $-0.59^{* * *}$ & $-0.70^{* * *}$ & $-0.83^{* * *}$ & $-0.85^{* * *}$ \\
\hline & $(0.04)$ & $(0.07)$ & $(0.06)$ & $(0.02)$ & $(0.08)$ & $(0.08)$ \\
\hline \multirow[t]{2}{*}{ contig } & $0.48^{* *}$ & $0.45^{* * *}$ & $0.35^{* *}$ & $0.43^{* * * *}$ & 0.23 & 0.19 \\
\hline & $(0.15)$ & $(0.11)$ & $(0.11)$ & $(0.05)$ & $(0.14)$ & $(0.14)$ \\
\hline \multirow[t]{2}{*}{ colony } & 0.18 & $0.38^{* *}$ & $0.32^{* *}$ & $0.64^{* * *}$ & $0.43^{* *}$ & $0.38^{* *}$ \\
\hline & $(0.16)$ & $(0.14)$ & $(0.12)$ & $(0.07)$ & $(0.14)$ & $(0.13)$ \\
\hline \multirow[t]{2}{*}{$\mathrm{rta}$} & $0.26^{* * *}$ & $0.50^{* * *}$ & $0.51^{* * *}$ & $0.76^{* * *}$ & $0.43^{* * *}$ & $0.42^{* * *}$ \\
\hline & $(0.07)$ & $(0.10)$ & $(0.11)$ & $(0.05)$ & $(0.10)$ & $(0.10)$ \\
\hline \multirow[t]{2}{*}{$\operatorname{lng}$} & $0.92^{* * *}$ & 0.09 & 0.02 & 0.08 & $0.37^{* *}$ & $0.34^{*}$ \\
\hline & $(0.10)$ & $(0.14)$ & $(0.13)$ & $(0.07)$ & $(0.14)$ & $(0.14)$ \\
\hline \multirow[t]{2}{*}{ comleg } & $0.44^{* * *}$ & $0.21^{* *}$ & $0.22^{* *}$ & $0.38^{* * *}$ & $0.25^{* * *}$ & $0.25^{* * *}$ \\
\hline & $(0.06)$ & $(0.07)$ & $(0.07)$ & $(0.05)$ & $(0.07)$ & $(0.07)$ \\
\hline \multirow[t]{2}{*}{ leg.qlt } & $0.20^{* * *}$ & $0.18^{* * *}$ & $0.16^{* * *}$ & $0.23^{* * *}$ & 0.00 & 0.00 \\
\hline & $(0.04)$ & $(0.05)$ & $(0.05)$ & $(0.02)$ & $(0.04)$ & $(0.04)$ \\
\hline \multirow[t]{2}{*}{ dpati } & $0.27^{*}$ & -0.19 & -0.18 & $0.59^{* * *}$ & 0.09 & 0.07 \\
\hline & $(0.11)$ & $(0.14)$ & $(0.13)$ & $(0.05)$ & $(0.16)$ & $(0.16)$ \\
\hline \multirow[t]{2}{*}{ drisk } & -0.17 & 0.44 & 0.42 & $0.43^{* *}$ & -0.47 & -0.48 \\
\hline & $(0.14)$ & $(0.23)$ & $(0.23)$ & $(0.14)$ & $(0.38)$ & $(0.38)$ \\
\hline \multirow[t]{2}{*}{ dposrec } & $-0.23^{*}$ & $0.31^{\circ}$ & 0.28 & $0.35^{* * *}$ & 0.01 & 0.02 \\
\hline & $(0.11)$ & $(0.18)$ & $(0.17)$ & $(0.08)$ & $(0.10)$ & $(0.10)$ \\
\hline \multirow[t]{2}{*}{ dnegrec } & $0.28^{*}$ & $-0.46^{* * *}$ & $-0.47^{* * *}$ & $-0.20^{*}$ & $-0.18^{*}$ & $-0.18^{*}$ \\
\hline & $(0.14)$ & $(0.11)$ & $(0.11)$ & $(0.09)$ & $(0.08)$ & $(0.08)$ \\
\hline Observations & 4749 & 5112 & 4749 & 4749 & 5112 & 4749 \\
\hline Deviance & & $2139 \times 10^{9}$ & $1904 \times 10^{9}$ & & 35.28 & 32.72 \\
\hline Null Deviance & & $37598 \times 10^{9}$ & $36564 \times 10^{9}$ & & 252.74 & 242.14 \\
\hline $\mathrm{R}^{2}$ & 0.35 & & & 0.29 & & \\
\hline Adj. $\mathrm{R}^{2}$ & 0.32 & & & 0.26 & & \\
\hline Exp./Imp. FE & YES & YES & YES & YES & YES & YES \\
\hline
\end{tabular}

All estimations are based on model (2) of Table 4, i.e. the PPML estimation of single preference distances with legal quality as control variable and differentiated goods flow as dependent variable. These results are also displayed in column (2) of this table. Standard errors are clustered to Importer and Exporter fixed effects, identical to that model.

The alternative estimators follow Mayer et al. (2019), specifically their Table 3, in controlling for potential confounding effects of both large and zero trade flows. Column (1) provides the OLS equivalent of the PPML main equation, with zero flows excluded. Column (3) provides the same estimation, but via PPML. In column (4), the model is estimated with weighted least squares; level trade flows are used as weights. Columns (5) and (6) estimate the main PPML model with trade shares, i.e. bilateral imports divided by total imports of that importer, as dependent variable

${ }^{* * *} p<0.001,{ }^{* *} p<0.01,{ }^{*} p<0.05,{ }^{\dagger} p<0.1$ 
Table 12 Alternative estimators for bilateral exports in non-differentiated goods

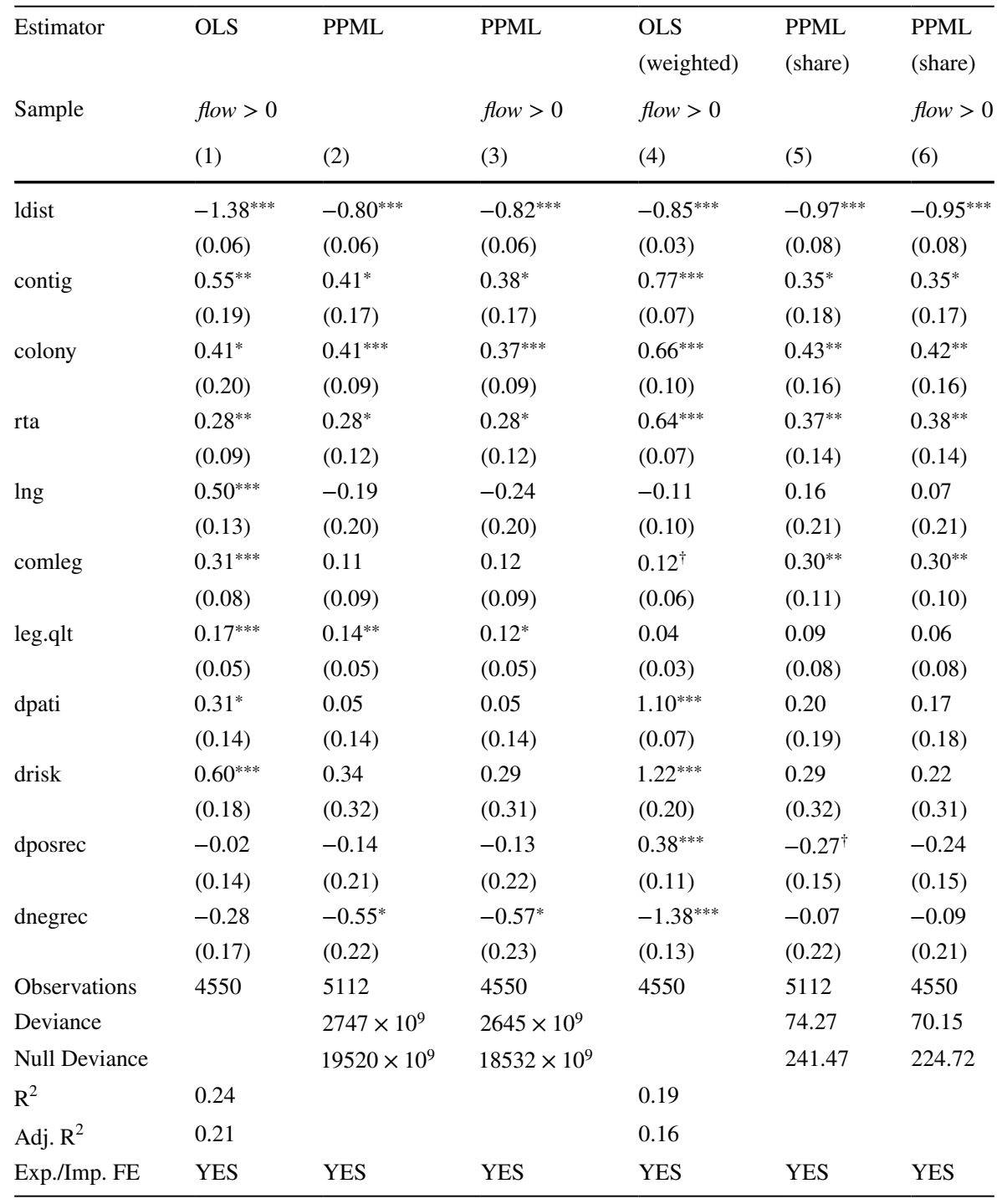

All estimations are based on model (4) of Table 4, i.e. the PPML estimation of single preference distances with legal quality as control variable and non-differentiated goods flow as dependent variable. These results are also displayed in column (2) of this table. Standard errors are clustered to Importer and Exporter fixed effects, identical to that model

The alternative estimators follow Mayer et al. (2019), specifically their Table 3, in controlling for potential confounding effects of both large and zero trade flows. Column (1) provides the OLS equivalent of the PPML main equation, with zero flows excluded. Column (3) provides the same estimation, but via PPML. In column (4), the model is estimated with weighted least squares; level trade flows are used as weights. Columns (5) and (6) estimate the main PPML model with trade shares, i.e. bilateral imports divided by total imports of that importer, as dependent variable

${ }^{* * *} p<0.001,{ }^{* *} p<0.01,{ }^{*} p<0.05,{ }^{\dagger} p<0.1$ 

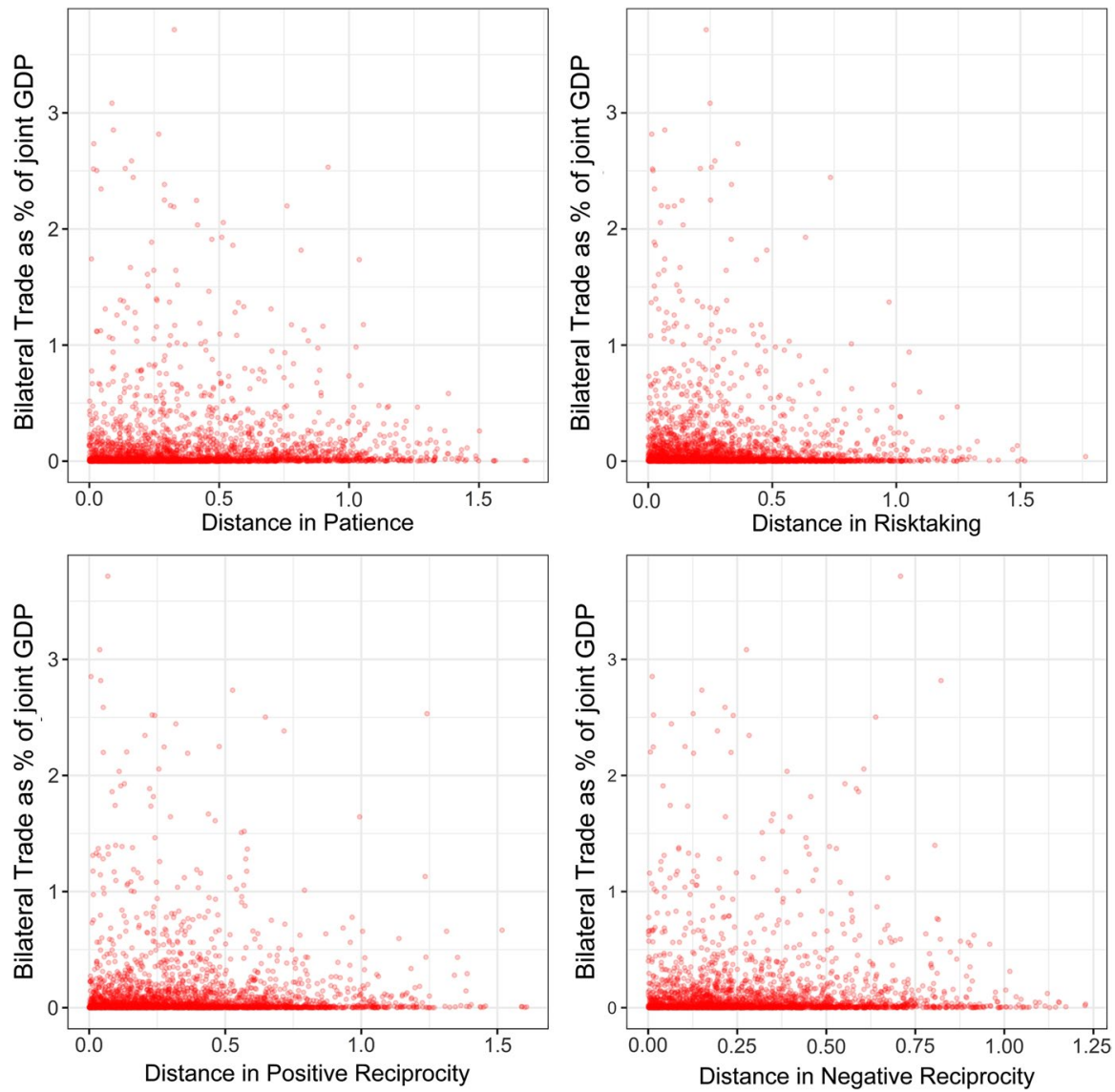

Fig. 2 Preference distance and trade volumes. Notes: This figure displays the relationship between the preference distances and the intensity of trade between a given country pair. The latter is measured as the bilateral trade between that pair, divided by their joint GDP 
Table 13 Robustness Estimations of Exporter Fixed Effects - Differentiated Goods

\begin{tabular}{|c|c|c|c|c|}
\hline & Baseline & Single Pref. & Single Pref. Rights & Single Pref. Legal \\
\hline \multirow[t]{2}{*}{ (Intercept) } & $22.97^{* * *}$ & $19.30^{* * *}$ & $19.17^{* * *}$ & $18.24^{* * *}$ \\
\hline & $(4.49)$ & $(4.66)$ & $(5.07)$ & $(4.74)$ \\
\hline \multirow[t]{2}{*}{ avg.char } & 0.64 & -0.35 & -0.58 & -0.63 \\
\hline & $(1.02)$ & (1.07) & $(1.05)$ & $(1.10)$ \\
\hline \multirow[t]{2}{*}{ pop } & $0.05^{* * *}$ & $0.04^{* *}$ & $0.04^{* * *}$ & $0.04^{* *}$ \\
\hline & $(0.01)$ & $(0.01)$ & $(0.01)$ & $(0.01)$ \\
\hline \multirow[t]{2}{*}{ gdpcap } & $0.78^{* * *}$ & $0.43^{*}$ & $0.43^{\dagger}$ & 0.28 \\
\hline & $(0.12)$ & $(0.21)$ & $(0.22)$ & $(0.25)$ \\
\hline \multirow[t]{2}{*}{ landlocked } & $-1.63^{*}$ & $-1.41^{*}$ & $-1.44^{*}$ & $-1.35^{*}$ \\
\hline & $(0.65)$ & $(0.67)$ & $(0.67)$ & $(0.67)$ \\
\hline \multirow[t]{2}{*}{ patience } & & $1.86^{\dagger}$ & 0.63 & 1.51 \\
\hline & & (1.06) & $(1.15)$ & (1.10) \\
\hline \multirow[t]{2}{*}{ risktaking } & & $-2.25^{*}$ & -1.49 & $-2.06^{*}$ \\
\hline & & $(0.90)$ & $(0.94)$ & $(0.91)$ \\
\hline \multirow[t]{2}{*}{ posrecip } & & 0.97 & 0.91 & 0.91 \\
\hline & & $(1.08)$ & $(1.06)$ & $(1.08)$ \\
\hline \multirow[t]{2}{*}{ negrecip } & & 0.64 & 1.41 & 0.73 \\
\hline & & $(0.89)$ & $(0.91)$ & $(0.89)$ \\
\hline \multirow[t]{2}{*}{ altruism } & & -0.84 & -0.90 & -0.70 \\
\hline & & $(1.02)$ & $(1.01)$ & $(1.02)$ \\
\hline \multirow[t]{2}{*}{ trust } & & 0.46 & 0.89 & 0.47 \\
\hline & & $(0.91)$ & $(0.94)$ & $(0.91)$ \\
\hline \multirow[t]{2}{*}{ 'PR Rating' } & & & $0.88^{\dagger}$ & \\
\hline & & & $(0.46)$ & \\
\hline \multirow[t]{2}{*}{ 'CL Rating' } & & & $-1.24^{*}$ & \\
\hline & & & $(0.48)$ & \\
\hline \multirow[t]{2}{*}{ Free } & & & 0.13 & \\
\hline & & & (1.90) & \\
\hline \multirow[t]{2}{*}{ PartFree } & & & 0.43 & \\
\hline & & & $(1.14)$ & \\
\hline \multirow[t]{2}{*}{ leg.qlt (level) } & & & & 0.48 \\
\hline & & & & $(0.42)$ \\
\hline $\mathrm{R}^{2}$ & 0.50 & 0.57 & 0.62 & 0.58 \\
\hline Adj. $R^{2}$ & 0.47 & 0.50 & 0.53 & 0.50 \\
\hline Num. obs. & 72 & 72 & 72 & 72 \\
\hline
\end{tabular}

${ }^{* * *} p<0.001,{ }^{* *} p<0.01,{ }^{*} p<0.05,{ }^{\dagger} p<0.1$

Notes: The Fixed Effects represent Average Trade Barriers and are estimated via a two-step approach for differentiated-goods only. Exporter fixed effects are extracted from Table 4 specification (2) and estimated via OLS using unilateral size and location variables, the average bilateral characteristics relating to the country in question and the single preference variables including altruism and trust. Column shows a regression on conventional country characteristics. (2) adds the single preferences in level, (3) and (4) add different institutional and legal quality controls. The results imply a relationship between risktaking and patience on one side and legal regimes on the other. However, these regressions must be treated with caution due to the high number of coefficients 
Table 14 Robustness Estimations of Exporter Fixed Effects - Non-Differentiated Goods

\begin{tabular}{|c|c|c|c|c|}
\hline & Baseline & Single Pref. & Single Pref. Rights & Single Pref. Legal \\
\hline \multirow[t]{2}{*}{ (Intercept) } & $19.34^{* * *}$ & $20.55^{* * *}$ & $21.65^{* * *}$ & $21.30^{* * *}$ \\
\hline & $(3.86)$ & $(4.05)$ & $(4.41)$ & $(4.13)$ \\
\hline \multirow[t]{2}{*}{ avg.char } & -0.63 & -0.39 & -0.51 & -0.27 \\
\hline & $(0.56)$ & $(0.59)$ & $(0.61)$ & $(0.61)$ \\
\hline \multirow[t]{2}{*}{ pop } & $0.03^{* *}$ & $0.03^{* * *}$ & $0.03^{* * *}$ & $0.03^{* * *}$ \\
\hline & $(0.01)$ & $(0.01)$ & $(0.01)$ & $(0.01)$ \\
\hline \multirow[t]{2}{*}{ gdpcap } & $0.53^{* * *}$ & $0.75^{* * *}$ & $0.71^{* * *}$ & $0.85^{* * *}$ \\
\hline & $(0.09)$ & $(0.16)$ & $(0.18)$ & $(0.19)$ \\
\hline \multirow[t]{2}{*}{ landlocked } & $-1.18^{*}$ & $-1.31^{*}$ & $-1.36^{*}$ & $-1.35^{*}$ \\
\hline & $(0.49)$ & $(0.51)$ & $(0.53)$ & $(0.51)$ \\
\hline \multirow[t]{2}{*}{ patience } & & $-1.60^{*}$ & -1.41 & -1.38 \\
\hline & & $(0.80)$ & $(0.90)$ & $(0.83)$ \\
\hline \multirow[t]{2}{*}{ risktaking } & & $1.96^{* *}$ & $1.95^{*}$ & $1.83^{*}$ \\
\hline & & $(0.68)$ & $(0.74)$ & $(0.69)$ \\
\hline \multirow[t]{2}{*}{ posrecip } & & 0.26 & 0.21 & 0.28 \\
\hline & & $(0.82)$ & $(0.83)$ & $(0.82)$ \\
\hline \multirow[t]{2}{*}{ negrecip } & & -0.20 & -0.36 & -0.26 \\
\hline & & $(0.68)$ & $(0.72)$ & $(0.68)$ \\
\hline \multirow[t]{2}{*}{ altruism } & & -0.50 & -0.43 & -0.59 \\
\hline & & $(0.77)$ & $(0.80)$ & $(0.77)$ \\
\hline \multirow[t]{2}{*}{ trust } & & 0.84 & 0.58 & 0.84 \\
\hline & & $(0.69)$ & $(0.74)$ & $(0.69)$ \\
\hline \multirow[t]{2}{*}{ 'PR Rating' } & & & -0.36 & \\
\hline & & & $(0.36)$ & \\
\hline \multirow[t]{2}{*}{ 'CL Rating' } & & & 0.13 & \\
\hline & & & $(0.38)$ & \\
\hline \multirow[t]{2}{*}{ Free } & & & -1.50 & \\
\hline & & & (1.49) & \\
\hline \multirow[t]{2}{*}{ PartFree } & & & -1.30 & \\
\hline & & & $(0.89)$ & \\
\hline \multirow[t]{2}{*}{ leg.qlt (level) } & & & & -0.30 \\
\hline & & & & $(0.32)$ \\
\hline $\mathrm{R}^{2}$ & 0.43 & 0.52 & 0.54 & 0.53 \\
\hline $\operatorname{Adj} . R^{2}$ & 0.39 & 0.44 & 0.43 & 0.44 \\
\hline Num. obs. & 72 & 72 & 72 & 72 \\
\hline
\end{tabular}

${ }^{* * *} p<0.001,{ }^{* *} p<0.01,{ }^{*} p<0.05,{ }^{\dagger} p<0.1$

Notes: The Fixed Effects represent Average Trade Barriers and are estimated via a two-step approach for non-differentiated-goods only. Exporter fixed effects are extracted from Table 4 specification (2) and estimated via OLS using unilateral size and location variables, the average bilateral characteristics relating to the country in question and the single preference variables including altruism and trust. Column (1) shows a regression on conventional country characteristics. (2) adds the single preferences in level, (3) and (4) add different institutional and legal quality controls. The results imply a relationship between risktaking and patience on one side and legal regimes on the other. However, these regressions must be treated with caution due to the high number of coefficients 
Table 15 Estimation fixed effects composition for breadth of trade

\begin{tabular}{|c|c|c|c|c|}
\hline & \multicolumn{2}{|c|}{ Differentiated goods } & \multicolumn{2}{|c|}{ Non-differentiated goods } \\
\hline & Exporter & Importer & Exporter & Importer \\
\hline & (1) & (2) & (3) & (4) \\
\hline \multirow[t]{2}{*}{ (Intercept) } & $4.76^{*}$ & -1.11 & $4.18^{\dagger}$ & -1.07 \\
\hline & (1.91) & $(0.84)$ & $(2.15)$ & (1.09) \\
\hline \multirow[t]{2}{*}{ avg.char } & -0.25 & -0.49 & -0.30 & -0.29 \\
\hline & $(0.99)$ & $(0.44)$ & $(0.74)$ & $(0.37)$ \\
\hline \multirow[t]{2}{*}{ spop } & $0.01^{* *}$ & $0.00^{* *}$ & $0.02^{* * *}$ & $0.01^{* * *}$ \\
\hline & $(0.00)$ & $(0.00)$ & $(0.00)$ & $(0.00)$ \\
\hline \multirow[t]{2}{*}{ sgdpcap } & $0.18^{*}$ & $0.08^{* *}$ & $0.24^{* *}$ & $0.12^{* *}$ \\
\hline & $(0.07)$ & $(0.03)$ & $(0.08)$ & $(0.04)$ \\
\hline \multirow[t]{2}{*}{ landlocked } & $-0.56^{*}$ & -0.09 & $-0.48^{\dagger}$ & -0.20 \\
\hline & $(0.21)$ & $(0.09)$ & $(0.25)$ & $(0.13)$ \\
\hline \multirow[t]{2}{*}{ patience } & 0.28 & 0.04 & 0.25 & 0.04 \\
\hline & $(0.35)$ & $(0.15)$ & $(0.41)$ & $(0.21)$ \\
\hline \multirow[t]{2}{*}{ risktaking } & $-0.51^{\dagger}$ & 0.05 & -0.26 & 0.04 \\
\hline & $(0.28)$ & $(0.12)$ & $(0.33)$ & $(0.17)$ \\
\hline \multirow[t]{2}{*}{ posrecip } & 0.14 & -0.09 & 0.08 & -0.01 \\
\hline & $(0.22)$ & $(0.10)$ & $(0.26)$ & (0.13) \\
\hline \multirow[t]{2}{*}{ negrecip } & 0.36 & 0.05 & 0.23 & 0.19 \\
\hline & $(0.29)$ & $(0.13)$ & $(0.34)$ & $(0.17)$ \\
\hline $\mathrm{R}^{2}$ & 0.52 & 0.37 & 0.52 & 0.46 \\
\hline Adj. $R^{2}$ & 0.45 & 0.27 & 0.44 & 0.37 \\
\hline Num. obs. & 72 & 72 & 72 & 72 \\
\hline
\end{tabular}

The Fixed Effects represent Average Trade Barriers and are estimated via a two-step approach. Exporter and importer fixed effects are extracted from Table 6 specifications (2) and (4)_for differentiated and non-differentiated goods - and estimated via OLS using unilateral size and location variables, the average bilateral characteristics relating to the country in question and the single preference variables. Columns (1) and (2) show country characteristics for differentiated goods and (3) and (4) for non-differentiated goods. Exporter results are displayed first in each case

${ }^{* * *} p<0.001,{ }^{* *} p<0.01,{ }^{*} p<0.05,{ }^{\dagger} p<0.1$ 
Table 16 OECD subset: preference distribution

\begin{tabular}{llllll}
\hline Statistic & N & Mean & St. Dev. & Min & Max \\
\hline patience & 25 & 0.317 & 0.416 & -0.431 & 1.071 \\
risktaking & 25 & -0.078 & 0.232 & -0.792 & 0.244 \\
posrecip & 25 & -0.073 & 0.284 & -1.038 & 0.316 \\
negrecip & 25 & 0.101 & 0.277 & -0.375 & 0.665 \\
altruism & 25 & -0.148 & 0.341 & -0.940 & 0.406 \\
trust & 25 & 0.021 & 0.260 & -0.519 & 0.532 \\
\hline
\end{tabular}

The single preferences are normalized to the individual level for the whole GPS sample, while the averages are calculated using only those GPS countries which are also in the OECD. For this reason, the means deviate from zero despite the normalization

Table 17 OECD subset: sumary statistics for distances in preferences

\begin{tabular}{llllll}
\hline Statistic & N & Mean & St. Dev. & Min & Max \\
\hline dpati & 600 & 0.485 & 0.332 & 0.0001 & 1.502 \\
drisk & 600 & 0.249 & 0.214 & 0.001 & 1.036 \\
dposrec & 600 & 0.296 & 0.272 & 0.004 & 1.354 \\
dnegrec & 600 & 0.321 & 0.224 & 0.001 & 1.040 \\
daltr & 600 & 0.386 & 0.290 & 0.002 & 1.346 \\
dtrus & 600 & 0.297 & 0.217 & 0.001 & 1.051 \\
dpref & 600 & 0.339 & 0.130 & 0.061 & 0.712 \\
\hline
\end{tabular}


Table 18 OECD subset: standard gravity

Basic Grav. Agg. Pref. Dist. Agg. Pref. Dist Single Pref. Dist. Single Pref. Dist.

$\begin{array}{llll}\text { (1) (2) (3) } & \text { (3) }\end{array}$

\begin{tabular}{|c|c|c|c|c|c|}
\hline ldist & $\begin{array}{l}-0.52^{* * *} \\
(0.08)\end{array}$ & $\begin{array}{l}-0.55^{* * *} \\
(0.08)\end{array}$ & $\begin{array}{l}-0.56^{* * *} \\
(0.08)\end{array}$ & $\begin{array}{l}-0.60^{* * *} \\
(0.06)\end{array}$ & $\begin{array}{l}-0.60^{* * *} \\
(0.06)\end{array}$ \\
\hline contig & $\begin{array}{l}0.69^{* * *} \\
(0.15)\end{array}$ & $\begin{array}{l}0.64^{* * *} \\
(0.14)\end{array}$ & $\begin{array}{l}0.63^{* * *} \\
(0.14)\end{array}$ & $\begin{array}{l}0.66^{* * *} \\
(0.12)\end{array}$ & $\begin{array}{l}0.66^{* * *} \\
(0.13)\end{array}$ \\
\hline colony & $\begin{array}{l}0.27^{*} \\
(0.13)\end{array}$ & $\begin{array}{l}0.23^{\dagger} \\
(0.12)\end{array}$ & $\begin{array}{l}0.19 \\
(0.12)\end{array}$ & $\begin{array}{l}0.28^{* *} \\
(0.11)\end{array}$ & $\begin{array}{l}0.24^{*} \\
(0.11)\end{array}$ \\
\hline rta & $\begin{array}{l}0.56^{* * *} \\
(0.13)\end{array}$ & $\begin{array}{l}0.52^{\text {*** }} \\
(0.12)\end{array}$ & $\begin{array}{l}0.50^{* * *} \\
(0.12)\end{array}$ & $\begin{array}{l}0.49^{* * *} \\
(0.11)\end{array}$ & $\begin{array}{l}0.47^{* * *} \\
(0.11)\end{array}$ \\
\hline $\operatorname{lng}$ & $\begin{array}{l}0.07 \\
(0.19)\end{array}$ & $\begin{array}{l}0.23 \\
(0.17)\end{array}$ & $\begin{array}{l}-0.03 \\
(0.18)\end{array}$ & $\begin{array}{l}0.09 \\
(0.17)\end{array}$ & $\begin{array}{l}-0.08 \\
(0.18)\end{array}$ \\
\hline dpref & & $\begin{array}{l}0.94 \\
(0.58)\end{array}$ & $\begin{array}{l}1.37^{*} \\
(0.56)\end{array}$ & & \\
\hline comleg & & & $\begin{array}{l}0.31^{* * *} \\
(0.08)\end{array}$ & & $\begin{array}{l}0.21^{*} \\
(0.09)\end{array}$ \\
\hline leg.qlt & & & $\begin{array}{l}-0.05 \\
(0.13)\end{array}$ & & $\begin{array}{l}-0.11 \\
(0.12)\end{array}$ \\
\hline dpati & & & & $\begin{array}{l}0.39^{*} \\
(0.17)\end{array}$ & $\begin{array}{l}0.57^{* * * *} \\
(0.15)\end{array}$ \\
\hline drisk & & & & $\begin{array}{l}-0.26 \\
(0.59)\end{array}$ & $\begin{array}{l}-0.32 \\
(0.62)\end{array}$ \\
\hline dposrec & & & & $\begin{array}{l}1.24^{* * *} \\
(0.30)\end{array}$ & $\begin{array}{l}1.25^{* * * *} \\
(0.32)\end{array}$ \\
\hline dnegrec & & & & $\begin{array}{l}-0.66^{* * *} \\
(0.10)\end{array}$ & $\begin{array}{l}-0.52^{* * *} \\
(0.11)\end{array}$ \\
\hline Observations & 600 & 600 & 600 & 600 & 600 \\
\hline Deviance & $1067 \times 10^{9}$ & $1043 \times 10^{9}$ & $1006 \times 10^{9}$ & $9215 \times 10^{9}$ & $9031 \times 10^{9}$ \\
\hline Null Deviance & $137327 \times 10^{9}$ & $13732 \times 10^{9}$ & $13732 \times 10^{9}$ & $13732 \times 10^{9}$ & $13732 \times 10^{9}$ \\
\hline Exp./Imp. FE & YES & YES & YES & YES & YES \\
\hline
\end{tabular}

The estimation of aggregated bilateral exports $X_{i j}$ of all members of the OECD included in the GPS dataset is conducted via PPML. The variables of interest are the distances in preferences, included as an unweighted average dpref in $(2,3)$ and as single variables dpati, drisk, dposrec, dnegrec $(4,5)$. Commonalities in legal systems are included in models (3) and (5) due to their potential impact on negotiations, the channel of interest. Model (1) is a standard gravity equation for comparison. Standard errors are clustered to Importer and Exporter fixed effects.

It can be seen that the negative coefficient and significance for dnegrec remains. However, the weak effect of distances in risk does not carry over to the OECD set, while distance in positive reciprocity has a significant positive impact on volumes here, supporting the hypothesis of a beneficial effect from corresponding gestures- - e.g. gifts, perceptions of fairness

${ }^{* * *} p<0.001,{ }^{* *} p<0.01,{ }^{*} p<0.05,{ }^{\dagger} p<0.1$ 
Table 19 OECD subset: differentiated and non-differentiated goods

\begin{tabular}{|c|c|c|c|c|}
\hline & \multicolumn{2}{|c|}{ Differentiated Goods } & \multicolumn{2}{|c|}{ Non-Differentiated Goods } \\
\hline & $\begin{array}{l}\text { Agg. Pref. Dist. } \\
\text { (1) }\end{array}$ & $\begin{array}{l}\text { Single Pref. Dist. } \\
\text { (2) }\end{array}$ & $\begin{array}{l}\text { Agg. Pref. Dist. } \\
\text { (3) }\end{array}$ & $\begin{array}{l}\text { Single Pref. Dist. } \\
\text { (4) }\end{array}$ \\
\hline ldist & $\begin{array}{l}-0.46^{* * *} \\
(0.08)\end{array}$ & $\begin{array}{l}-0.49^{* * *} \\
(0.07)\end{array}$ & $\begin{array}{l}-0.81^{* * *} \\
(0.09)\end{array}$ & $\begin{array}{l}-0.86^{* * *} \\
(0.09)\end{array}$ \\
\hline contig & $\begin{array}{l}0.59^{* * *} \\
(0.15)\end{array}$ & $\begin{array}{l}0.62^{* * *} \\
(0.13)\end{array}$ & $\begin{array}{l}0.70^{* * * *} \\
(0.17)\end{array}$ & $\begin{array}{l}0.72 * * * \\
(0.15)\end{array}$ \\
\hline colony & $\begin{array}{l}0.21 \\
(0.14)\end{array}$ & $\begin{array}{l}0.26^{*} \\
(0.12)\end{array}$ & $\begin{array}{l}0.24^{\dagger} \\
(0.12)\end{array}$ & $\begin{array}{l}0.30^{*} \\
(0.12)\end{array}$ \\
\hline rta & $\begin{array}{l}0.64^{* * *} \\
(0.14)\end{array}$ & $\begin{array}{l}0.62^{* * *} \\
(0.13)\end{array}$ & $\begin{array}{l}0.26 \\
(0.16)\end{array}$ & $\begin{array}{l}0.19 \\
(0.16)\end{array}$ \\
\hline $\operatorname{lng}$ & $\begin{array}{l}0.04 \\
(0.22)\end{array}$ & $\begin{array}{l}-0.01 \\
(0.20)\end{array}$ & $\begin{array}{l}-0.19 \\
(0.20)\end{array}$ & $\begin{array}{l}-0.27 \\
(0.19)\end{array}$ \\
\hline comleg & $\begin{array}{l}0.28^{* * *} \\
(0.08)\end{array}$ & $\begin{array}{l}0.19^{*} \\
(0.09)\end{array}$ & $\begin{array}{l}0.43^{* * *} \\
(0.06)\end{array}$ & $\begin{array}{l}0.33^{* * *} \\
(0.10)\end{array}$ \\
\hline leg.qlt & $\begin{array}{l}-0.03 \\
(0.14)\end{array}$ & $\begin{array}{l}-0.11 \\
(0.12)\end{array}$ & $\begin{array}{l}-0.07 \\
(0.12)\end{array}$ & $\begin{array}{l}-0.07 \\
(0.14)\end{array}$ \\
\hline dpref & $\begin{array}{l}1.17^{*} \\
(0.54)\end{array}$ & & $\begin{array}{l}1.58^{*} \\
(0.69)\end{array}$ & \\
\hline dpati & & $\begin{array}{l}0.57^{* *} \\
(0.18)\end{array}$ & & $\begin{array}{l}0.53^{* * * *} \\
(0.15)\end{array}$ \\
\hline drisk & & $\begin{array}{l}-0.23 \\
(0.56)\end{array}$ & & $\begin{array}{l}-0.85 \\
(0.73)\end{array}$ \\
\hline dprec & & $\begin{array}{l}1.14^{* * * *} \\
(0.33)\end{array}$ & & $\begin{array}{l}1.48^{* * *} \\
(0.34)\end{array}$ \\
\hline dnrec & & $\begin{array}{l}-0.62^{* * *} \\
(0.09)\end{array}$ & & $\begin{array}{l}-0.31 \\
(0.22)\end{array}$ \\
\hline Observations & 600.00 & 600.00 & 600.00 & 600.00 \\
\hline Deviance & $716 \times 10^{9}$ & $639 \times 10^{9}$ & $397 \times 10^{9}$ & $366 \times 10^{9}$ \\
\hline Null Deviance & $9691 \times 10^{9}$ & $9691 \times 10^{9}$ & $4702 \times 10^{9}$ & $4702 \times 10^{9}$ \\
\hline Exp./Imp. FE & YES & YES & YES & YES \\
\hline
\end{tabular}

Bilateral exports are estimated separately for differentiated and non-differentiated goods, which are partitioned using Rauch (1999) three-digit SITC classifications. The variables of interest are the distances in preferences, included as an unweighted average dpref in $(1,2)$ and as single variables dpati, drisk, dposrec, dnegrec $(3,4)$. Standard errors are clustered to Importer and Exporter fixed effects

In the OECD-set, it can be observed that the distance in patience positively impacts the volume and breadth of bilateral trade, supporting the specialization and term transformation hypothesis. The average level of patience for OECD countries is higher than in the GPS sample, implying a greater drive for specialization which would then provide greater opportunities for gains from trade

Distance in negative reciprocity is similar in size and direction to the full results, though insignificant for non-differentiated goods. It must be noted, however, that non-differentiated goods trade matters less within the OECD than in the full sample, accounting for $31 \%$ of the volume compared to $37 \%$ for the full set

${ }^{* * *} p<0.001,{ }^{* *} p<0.01,{ }^{*} p<0.05,{ }^{\dagger} p<0.1$ 
Table 20 OECD subset: breadth of trade

\begin{tabular}{|c|c|c|c|c|}
\hline & (1) & (2) & (3) & $\begin{array}{l}\text { Non-Dif- } \\
\text { ferentiated } \\
\text { Goods } \\
\text { (4) }\end{array}$ \\
\hline ldist & $\begin{array}{l}-0.09^{* *} \\
(0.03)\end{array}$ & $\begin{array}{l}-0.09^{* *} \\
(0.03)\end{array}$ & $\begin{array}{l}-0.04^{\dagger} \\
(0.02)\end{array}$ & $\begin{array}{l}-0.16^{* * *} \\
(0.04)\end{array}$ \\
\hline contig & $\begin{array}{l}-0.09^{*} \\
(0.04)\end{array}$ & $\begin{array}{l}-0.08^{*} \\
(0.04)\end{array}$ & $\begin{array}{l}-0.07^{\dagger} \\
(0.04)\end{array}$ & $\begin{array}{l}-0.13^{*} \\
(0.05)\end{array}$ \\
\hline colony & $\begin{array}{l}0.09 * \\
(0.04)\end{array}$ & $\begin{array}{l}0.07^{\dagger} \\
(0.04)\end{array}$ & $\begin{array}{l}0.05 \\
(0.04)\end{array}$ & $\begin{array}{l}0.12^{*} \\
(0.05)\end{array}$ \\
\hline $\mathrm{rta}$ & $\begin{array}{l}0.04 \\
(0.03)\end{array}$ & $\begin{array}{l}0.02 \\
(0.02)\end{array}$ & $\begin{array}{l}0.00 \\
(0.02)\end{array}$ & $\begin{array}{l}0.07 \\
(0.04)\end{array}$ \\
\hline $\operatorname{lng}$ & $\begin{array}{l}0.06^{* *} \\
(0.02)\end{array}$ & $\begin{array}{l}0.04 \\
(0.03)\end{array}$ & $\begin{array}{l}0.04 \\
(0.03)\end{array}$ & $\begin{array}{l}0.05 \\
(0.04)\end{array}$ \\
\hline comleg & & $\begin{array}{l}0.05^{* *} \\
(0.02)\end{array}$ & $\begin{array}{l}0.03^{* *} \\
(0.01)\end{array}$ & $\begin{array}{l}0.09^{* *} \\
(0.03)\end{array}$ \\
\hline leg.qlt & & $\begin{array}{l}-0.05^{\dagger} \\
(0.02)\end{array}$ & $\begin{array}{l}-0.04^{\dagger} \\
(0.03)\end{array}$ & $\begin{array}{l}-0.05^{*} \\
(0.03)\end{array}$ \\
\hline dpati & & $\begin{array}{l}0.16^{* *} \\
(0.05)\end{array}$ & $\begin{array}{l}0.15^{*} \\
(0.06)\end{array}$ & $\begin{array}{l}0.19^{* * * *} \\
(0.05)\end{array}$ \\
\hline drisk & & $\begin{array}{l}-0.10 \\
(0.06)\end{array}$ & $\begin{array}{l}-0.09 \\
(0.06)\end{array}$ & $\begin{array}{l}-0.12 \\
(0.10)\end{array}$ \\
\hline dposrec & & $\begin{array}{l}0.05^{* *} \\
(0.02)\end{array}$ & $\begin{array}{l}0.01 \\
(0.02)\end{array}$ & $\begin{array}{l}0.14^{* * *} \\
(0.03)\end{array}$ \\
\hline dnegrec & & $\begin{array}{l}-0.04 \\
(0.03)\end{array}$ & $\begin{array}{l}-0.03 \\
(0.03)\end{array}$ & $\begin{array}{l}-0.06 \\
(0.05)\end{array}$ \\
\hline Observations & 600 & 600 & 600 & 600 \\
\hline Deviance & 3156.23 & 3031.38 & 1730.66 & 1845.74 \\
\hline Null Deviance & 7788.43 & 7788.43 & 3449.64 & 6048.46 \\
\hline Exp./Imp. FE & YES & YES & YES & YES \\
\hline
\end{tabular}

Breadth of Trade is defined as the number of three-digit SITC goods categories with non-zero export values, i.e. $T_{i j}=\sum_{c} t_{c i j}$. The variables of interest are the distances in preferences, included as single variables dpati, drisk, dposrec, dnegrec (2). Model (1) is a standard gravity equation for comparison, specifications (3) and (4) estimate differentiated and non-differentiated goods, respectively. Standard errors are clustered to importer and exporter fixed effects

In contrast to the full set, dposrec has a positive effect on the extensive margin of trade within the OECD. The positive and significant impact of a distance in patience on trade volumes can be observed in both sets

${ }^{* * *} p<0.001,{ }^{* *} p<0.01,{ }^{*} p<0.05,{ }^{\dagger} p<0.1$ 
Table 21 OECD subset: alternative estimators for bilateral exports in differentiated goods

\begin{tabular}{|c|c|c|c|c|c|c|}
\hline \multirow{3}{*}{$\begin{array}{l}\text { Estimator } \\
\text { Sample }\end{array}$} & OLS & PPML & PPML & $\begin{array}{l}\text { OLS } \\
\text { (weighted) }\end{array}$ & $\begin{array}{l}\text { PPML } \\
\text { (share) }\end{array}$ & \multirow{3}{*}{$\begin{array}{l}\text { PPML } \\
\text { (share) } \\
\text { flow }>0 \\
\text { (6) }\end{array}$} \\
\hline & \multicolumn{2}{|l|}{ flow $>0$} & flow $>0$ & \multicolumn{2}{|l|}{ flow $>0$} & \\
\hline & (1) & (2) & (3) & (4) & (5) & \\
\hline \multirow[t]{2}{*}{ ldist } & $-0.91^{\text {**** }}$ & $-0.49^{* * *}$ & $-0.57^{* * *}$ & $-0.63^{* * * *}$ & $-0.60^{* * *}$ & $-0.65^{* * *}$ \\
\hline & $(0.05)$ & $(0.07)$ & $(0.04)$ & $(0.04)$ & $(0.08)$ & $(0.06)$ \\
\hline \multirow[t]{2}{*}{ contig } & 0.05 & $0.62^{* * *}$ & $0.47^{* * *}$ & $0.59^{* * *}$ & $0.51^{* * *}$ & $0.42^{* * *}$ \\
\hline & $(0.13)$ & $(0.13)$ & $(0.07)$ & $(0.07)$ & $(0.13)$ & $(0.12)$ \\
\hline \multirow[t]{2}{*}{ colony } & 0.19 & $0.26^{*}$ & $0.20^{\dagger}$ & $0.26^{* *}$ & 0.12 & 0.05 \\
\hline & $(0.14)$ & $(0.12)$ & $(0.11)$ & $(0.10)$ & $(0.20)$ & $(0.17)$ \\
\hline \multirow[t]{2}{*}{ rta } & $0.54^{* * *}$ & $0.62^{* * *}$ & $0.66^{* * *}$ & $0.86^{* * *}$ & $0.51^{* * *}$ & $0.53^{* * *}$ \\
\hline & $(0.11)$ & $(0.13)$ & $(0.14)$ & $(0.09)$ & $(0.14)$ & $(0.15)$ \\
\hline \multirow[t]{2}{*}{ col } & 0.17 & -0.01 & -0.10 & $-0.22^{\dagger}$ & 0.07 & -0.02 \\
\hline & $(0.15)$ & $(0.20)$ & (0.19) & $(0.12)$ & $(0.20)$ & $(0.20)$ \\
\hline \multirow[t]{2}{*}{ comleg } & $0.27^{* * *}$ & $0.19^{*}$ & $0.21^{*}$ & $0.26^{* *}$ & $0.27^{*}$ & $0.28^{*}$ \\
\hline & $(0.08)$ & (0.09) & $(0.10)$ & $(0.08)$ & $(0.12)$ & $(0.12)$ \\
\hline \multirow[t]{2}{*}{ leg.qlt } & $-0.16^{*}$ & -0.11 & -0.12 & -0.02 & -0.08 & -0.11 \\
\hline & $(0.08)$ & $(0.12)$ & $(0.13)$ & $(0.11)$ & $(0.13)$ & $(0.13)$ \\
\hline \multirow[t]{2}{*}{ dpati } & $0.32^{*}$ & $0.57^{* *}$ & $0.48^{* *}$ & $0.69^{* * *}$ & $0.45^{*}$ & $0.39^{*}$ \\
\hline & $(0.12)$ & $(0.18)$ & $(0.15)$ & $(0.18)$ & $(0.19)$ & $(0.19)$ \\
\hline \multirow[t]{2}{*}{ drisk } & $-0.40^{\dagger}$ & -0.23 & -0.07 & 0.01 & -0.34 & -0.25 \\
\hline & $(0.22)$ & $(0.56)$ & $(0.48)$ & $(0.36)$ & $(0.44)$ & $(0.38)$ \\
\hline \multirow[t]{2}{*}{ dprec } & -0.07 & $1.14^{* * *}$ & $1.10^{* *}$ & $1.80^{* * *}$ & 0.64 & 0.58 \\
\hline & $(0.18)$ & $(0.33)$ & $(0.34)$ & $(0.19)$ & $(0.41)$ & $(0.41)$ \\
\hline \multirow[t]{2}{*}{ dnrec } & $-0.27^{*}$ & $-0.62^{* * *}$ & $-0.65^{* * *}$ & $-1.08^{* * *}$ & $-0.47^{* * *}$ & $-0.45^{* * *}$ \\
\hline & $(0.14)$ & $(0.09)$ & $(0.08)$ & $(0.16)$ & $(0.09)$ & $(0.10)$ \\
\hline Observations & 594 & 600 & 594 & 594 & 600 & 594 \\
\hline Deviance & & $639 \times 10^{9}$ & $450 \times 10^{9}$ & & 5.90 & 4.71 \\
\hline Null Deviance & & $9691 \times 10^{9}$ & $9624 \times 10^{9}$ & & 46.70 & 46.20 \\
\hline $\mathrm{R}^{2}$ & 0.60 & & & 0.44 & & \\
\hline Adj. $R^{2}$ & 0.55 & & & 0.38 & & \\
\hline Exp./Imp. FE & YES & YES & YES & YES & YES & YES \\
\hline
\end{tabular}

All estimations are based on model (2) of Table 19, i.e. the PPML estimation of single preference distances with legal quality as control variable and differentiated goods flow as dependent variable for the OECD subset. These results are also displayed in column (2) of this table. Standard errors are clustered to Importer and Exporter fixed effects, identical to that model

The alternative estimators follow Mayer et al. (2019), specifically their Table 3, in controlling for potential confounding effects of both large and zero trade flows. Column (1) provides the OLS equivalent of the PPML main equation, with zero flows excluded. Column (3) provides the same estimation, but via PPML. In column (4), the model is estimated with weighted least squares; level trade flows are used as weights. Columns (5) and (6) estimate the main PPML model with trade shares, i.e. bilateral imports divided by total imports of that importer, as dependent variable

${ }^{* * *} p<0.001,{ }^{* *} p<0.01,{ }^{*} p<0.05,{ }^{\dagger} p<0.1$ 
Table 22 Estimation of goods category-specific exports with squared preference distances

\begin{tabular}{|c|c|c|c|c|}
\hline & \multicolumn{2}{|c|}{ Differentiated Goods } & \multicolumn{2}{|c|}{ Non-Differentiated Goods } \\
\hline & $\begin{array}{l}\text { Agg. Pref. Dist. } \\
\text { (1) }\end{array}$ & $\begin{array}{l}\text { Single Pref. Dist. } \\
\text { (2) }\end{array}$ & $\begin{array}{l}\text { Agg. Pref. Dist. } \\
\text { (3) }\end{array}$ & $\begin{array}{l}\text { Single Pref. Dist. } \\
\text { (4) }\end{array}$ \\
\hline ldist & $\begin{array}{l}-0.54^{* * *} \\
(0.07)\end{array}$ & $\begin{array}{l}-0.53^{* * *} \\
(0.07)\end{array}$ & $\begin{array}{l}-0.80^{* * *} \\
(0.07)\end{array}$ & $\begin{array}{l}-0.80^{* * *} \\
(0.07)\end{array}$ \\
\hline contig & $\begin{array}{l}0.45^{* * *} \\
(0.11)\end{array}$ & $\begin{array}{l}0.45^{* * *} \\
(0.11)\end{array}$ & $\begin{array}{l}0.42^{*} \\
(0.18)\end{array}$ & $\begin{array}{l}0.43^{*} \\
(0.17)\end{array}$ \\
\hline colony & $\begin{array}{l}0.33^{*} \\
(0.15)\end{array}$ & $\begin{array}{l}0.36^{*} \\
(0.15)\end{array}$ & $\begin{array}{l}0.43^{* * *} \\
(0.10)\end{array}$ & $\begin{array}{l}0.42^{* * *} \\
(0.10)\end{array}$ \\
\hline $\mathrm{rta}$ & $\begin{array}{l}0.47^{* * *} \\
(0.10)\end{array}$ & $\begin{array}{l}0.52^{* * *} \\
(0.10)\end{array}$ & $\begin{array}{l}0.26^{*} \\
(0.12)\end{array}$ & $\begin{array}{l}0.28^{*} \\
(0.12)\end{array}$ \\
\hline $\operatorname{lng}$ & $\begin{array}{l}0.10 \\
(0.15)\end{array}$ & $\begin{array}{l}0.07 \\
(0.15)\end{array}$ & $\begin{array}{l}-0.21 \\
(0.18)\end{array}$ & $\begin{array}{l}-0.20 \\
(0.19)\end{array}$ \\
\hline comleg & $\begin{array}{l}0.24^{* * *} \\
(0.07)\end{array}$ & $\begin{array}{l}0.23^{* * *} \\
(0.07)\end{array}$ & $\begin{array}{l}0.12 \\
(0.08)\end{array}$ & $\begin{array}{l}0.12 \\
(0.08)\end{array}$ \\
\hline leg.qlt & $\begin{array}{l}0.17^{* * *} \\
(0.04)\end{array}$ & $\begin{array}{l}0.21^{* * *} \\
(0.04)\end{array}$ & $\begin{array}{l}0.16^{* *} \\
(0.05)\end{array}$ & $\begin{array}{l}0.15^{*} \\
(0.06)\end{array}$ \\
\hline dpref & $\begin{array}{l}-0.14 \\
(0.37)\end{array}$ & & $\begin{array}{l}-0.30 \\
(0.31)\end{array}$ & \\
\hline dpati & & $\begin{array}{l}-0.23^{*} \\
(0.11)\end{array}$ & & $\begin{array}{l}0.01 \\
(0.10)\end{array}$ \\
\hline drisk & & $\begin{array}{l}0.28 \\
(0.26)\end{array}$ & & $\begin{array}{l}0.40 \\
(0.35)\end{array}$ \\
\hline dprec & & $\begin{array}{l}0.35^{* *} \\
(0.13)\end{array}$ & & $\begin{array}{l}-0.05 \\
(0.19)\end{array}$ \\
\hline dnrec & & $\begin{array}{l}-0.34^{* * *} \\
(0.09)\end{array}$ & & $\begin{array}{l}-0.60^{\dagger} \\
(0.31)\end{array}$ \\
\hline Observations & 5112 & 5112 & 5112 & 5112 \\
\hline Deviance & $2192 \times 10^{9}$ & $2149 \times 10^{9}$ & $2784 \times 10^{9}$ & $2757 \times 10^{9}$ \\
\hline Null Deviance & $37598 \times 10^{9}$ & $37598 \times 10^{9}$ & $19520 \times 10^{9}$ & $19520 \times 10^{9}$ \\
\hline Exp./Imp. FE & YES & YES & YES & YES \\
\hline
\end{tabular}

For this estimation, aggregated bilateral exports are split into differentiated and non-differentiated goods according to Rauch Rauch (1999) three-digit SITC classifications. The variables of interest are the distances in preferences, included as an unweighted average dpref in $(1,2)$ and as single variables dpati, drisk, dposrec, dnegrec $(3,4)$, which are the squared differences of the country pair in question. Standard errors are clustered to Importer and Exporter fixed effects

${ }^{* * *} p<0.001,{ }^{* *} p<0.01,{ }^{*} p<0.05,{ }^{\dagger} p<0.1$ 
Table 23 Estimation of goods category-specific exports with maximum preference values of country pairs

Differentiated goods

(1)

\begin{tabular}{lll}
\hline ldist & $-0.54^{* * *}$ & $-0.80^{* * *}$ \\
& $(0.07)$ & $(0.06)$ \\
\hline contig & $0.45^{* * *}$ & $0.41^{*}$ \\
& $(0.11)$ & $(0.17)$ \\
colony & $0.38^{* *}$ & $0.41^{* * *}$ \\
& $(0.14)$ & $(0.09)$ \\
rta & $0.50^{* * *}$ & $0.28^{*}$ \\
& $(0.10)$ & $(0.12)$ \\
lng & 0.09 & -0.19 \\
& $(0.14)$ & $(0.20)$ \\
comleg & $0.21^{* *}$ & 0.11 \\
& $(0.07)$ & $(0.09)$ \\
leg.qlt & $0.18^{* * *}$ & $0.14^{* *}$ \\
& $(0.05)$ & $(0.05)$ \\
maxpati & -0.37 & 0.10 \\
& $(0.28)$ & $(0.28)$ \\
maxrisk & $0.89^{\dagger}$ & 0.67 \\
& $(0.46)$ & $(0.64)$ \\
maxprec & $0.61^{\dagger}$ & -0.28 \\
& $(0.36)$ & $(0.43)$ \\
maxnrec & $-0.93^{* * *}$ & $-1.10^{*}$ \\
Observations & $(0.23)$ & $(0.44)$ \\
Deviance & 5112 & 5112 \\
Null Deviance & $2139 \times 10^{9}$ & $2747 \times 10^{9}$ \\
Exp./Imp. FE & $37598 \times 10^{9}$ & $19520 \times 10^{9}$ \\
\hline & YES & YES \\
\hline
\end{tabular}

Non-differentiated goods

(3)

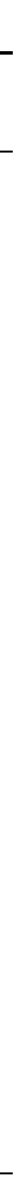


Table 24 Estimation of aggregated bilateral exports using World Values Survey

Agg. Pref. Dist. Agg. WVS Dist. Single Pref. Dist Single WVS Dist. Joined Dist.

(1)

\begin{tabular}{ll}
\hline ldist & $-0.59^{* *}$ \\
& $(0.06)$ \\
contig & $0.48^{* * *}$ \\
& $(0.14)$ \\
colony & $0.31^{* *}$ \\
& $(0.10)$ \\
rta & $0.32^{* *}$ \\
& $(0.10)$ \\
lng & -0.07 \\
& $(0.12)$ \\
comleg & $0.18^{*}$ \\
& $(0.07)$ \\
leg.qlt & $0.14^{* * *}$ \\
& $(0.02)$ \\
dpref (All) & -0.31 \\
& $(0.35)$
\end{tabular}

DWvsMean

1.01

(3.59)

dpati

drisk

dprec

dnrec

Drisk

Dtimepref

Observations

Deviance

5112.00

Null Deviance $52347 \times 10^{9}$

Exp./Imp. FE

(2)

(0.15)

(0.11)

(0.08)

$-0.03$

(0.09)

$0.15^{*}$

(0.07)

$0.13^{* *}$

(0.04)

$-0.57^{* * *}$
$(0.06)$

$0.49^{* * *}$

$0.37^{* * *}$

$0.39^{* * *}$

-0.16
$(0.10)$
$0.52^{\dagger}$
$(0.28)$
-0.04
$(0.18)$
$-0.53^{* * *}$
$(0.16)$

$-0.59^{* * *}$

(4)

$(0.06)$

$0.48^{* * *}$

(0.14)

$0.33^{* *}$

$(0.10)$

$0.35^{* * *}$

(0.09)

$-0.06$

(0.13)

$0.15^{*}$

(0.07)

$0.15^{* * *}$

(0.03)

(0.16)

$-0.10$

(1.35)

1.23 *

(0.55)

2156.00

0.04

(0.18)

$-0.42^{*}$

(0.16)

$-0.26$

(1.24)

$1.18^{*}$

(0.53)

2156.00

3192.00
$3702 \times 10^{9}$
$42633 \times 10^{9}$
YES

5112.00

$4562 \times 10^{9}$

$52347 \times 10^{9}$

YES
$2779 \times 10^{9}$

$2758 \times 10^{9}$

$35412 \times 10^{9}$

$35412 \times 10^{9}$

YES
YES

Models (1) and (3) include the unweighted average of the preference distances and the single preference distances, respectively. Models (2) and (4) replace these values with information from the World Values Survey, as defined by Jaeggi et al. (2018) for contrast and comparison. In Model (5), the two surveys are joined, with the WVS measures replacing their Falk equivalents

${ }^{* * *} p<0.001,{ }^{* *} p<0.01,{ }^{*} p<0.05,{ }^{\dagger} p<0.1$ 
Table 25 Hofstede \& GPS

\begin{tabular}{|c|c|c|c|c|}
\hline & \multicolumn{4}{|c|}{ Second Stage: Exporter } \\
\hline & \multicolumn{2}{|c|}{ Differentiated Goods } & \multicolumn{2}{|c|}{ Non-Differentiated Goods } \\
\hline & (1) & (2) & (3) & (4) \\
\hline \multirow[t]{2}{*}{ (Intercept) } & $20.80^{* * *}$ & $16.46^{* *}$ & $21.09^{* * *}$ & $12.40^{* *}$ \\
\hline & $(4.53)$ & $(4.74)$ & $(3.75)$ & $(4.08)$ \\
\hline \multirow[t]{2}{*}{ avg.char } & -0.03 & -1.03 & -0.31 & $-1.59^{* *}$ \\
\hline & $(1.00)$ & $(0.99)$ & $(0.54)$ & $(0.56)$ \\
\hline \multirow[t]{2}{*}{ spop } & $0.04^{* *}$ & $0.03^{*}$ & $0.03^{* * *}$ & $0.02^{* *}$ \\
\hline & $(0.01)$ & $(0.01)$ & $(0.01)$ & $(0.01)$ \\
\hline \multirow[t]{2}{*}{ sgdpcap } & $0.46^{*}$ & $0.32^{* *}$ & $0.79^{* * *}$ & $0.41^{* * * *}$ \\
\hline & $(0.20)$ & $(0.12)$ & $(0.15)$ & $(0.09)$ \\
\hline \multirow[t]{2}{*}{ landlocked } & $-1.46^{*}$ & -0.11 & $-1.26^{* *}$ & -0.65 \\
\hline & $(0.62)$ & $(0.78)$ & $(0.47)$ & $(0.62)$ \\
\hline \multirow[t]{2}{*}{ patience } & $1.93^{\dagger}$ & & $-1.68^{*}$ & \\
\hline & $(1.04)$ & & $(0.78)$ & \\
\hline \multirow[t]{2}{*}{ risktaking } & $-2.21^{* *}$ & & $1.90^{* *}$ & \\
\hline & $(0.81)$ & & $(0.61)$ & \\
\hline \multirow[t]{2}{*}{ uai } & & 0.00 & & 0.02 \\
\hline & & $(0.01)$ & & $(0.01)$ \\
\hline \multirow[t]{2}{*}{ ltowvs } & & $0.02^{*}$ & & -0.00 \\
\hline & & $(0.01)$ & & $(0.01)$ \\
\hline $\mathrm{R}^{2}$ & 0.55 & 0.44 & 0.50 & 0.50 \\
\hline Adj. $R^{2}$ & 0.51 & 0.35 & 0.46 & 0.42 \\
\hline \multirow[t]{4}{*}{ Num. obs. } & 72 & 44 & 72 & 44 \\
\hline & \multicolumn{4}{|c|}{ Second Stage: Importer } \\
\hline & \multicolumn{2}{|c|}{ Differentiated Goods } & \multicolumn{2}{|c|}{ Non-Differentiated Goods } \\
\hline & (5) & (6) & (7) & (8) \\
\hline \multirow[t]{2}{*}{ (Intercept) } & $21.09^{* * *}$ & $-7.32^{*}$ & -1.97 & $-9.68^{* *}$ \\
\hline & $(3.75)$ & $(3.43)$ & $(3.05)$ & $(3.29)$ \\
\hline \multirow[t]{2}{*}{ avg.char } & -0.31 & $-1.41^{\dagger}$ & -0.12 & $-1.20^{*}$ \\
\hline & $(0.54)$ & $(0.72)$ & $(0.44)$ & $(0.45)$ \\
\hline \multirow[t]{2}{*}{ spop } & $0.03^{* * *}$ & $0.02^{* *}$ & $0.04^{* * *}$ & $0.03^{* * *}$ \\
\hline & $(0.01)$ & $(0.01)$ & $(0.01)$ & $(0.01)$ \\
\hline \multirow[t]{2}{*}{ sgdpcap } & $0.79^{* * *}$ & $0.35^{* * *}$ & $0.57^{* * *}$ & $0.33^{* * *}$ \\
\hline & $(0.15)$ & $(0.08)$ & $(0.12)$ & $(0.07)$ \\
\hline \multirow[t]{2}{*}{ landlocked } & $-1.26^{* *}$ & -0.37 & $-1.00^{*}$ & -0.50 \\
\hline & $(0.47)$ & $(0.56)$ & $(0.38)$ & $(0.50)$ \\
\hline \multirow[t]{2}{*}{ patience } & $-1.68^{*}$ & & -0.35 & \\
\hline & $(0.78)$ & & $(0.64)$ & \\
\hline \multirow[t]{2}{*}{ risktaking } & $1.90^{* *}$ & & 0.19 & \\
\hline & $(0.61)$ & & $(0.50)$ & \\
\hline
\end{tabular}


Table 25 (continuted)

\begin{tabular}{|c|c|c|c|c|}
\hline & \multicolumn{4}{|c|}{ Second Stage: Importer } \\
\hline & \multicolumn{2}{|c|}{ Differentiated Goods } & \multicolumn{2}{|c|}{ Non-Differentiated Goods } \\
\hline & (5) & (6) & (7) & (8) \\
\hline \multirow[t]{2}{*}{ uai } & & 0.01 & & 0.01 \\
\hline & & $(0.01)$ & & $(0.01)$ \\
\hline \multirow[t]{2}{*}{ ltowvs } & & 0.00 & & 0.01 \\
\hline & & $(0.01)$ & & $(0.01)$ \\
\hline Adj. $\mathrm{R}^{2}$ & 0.46 & 0.38 & 0.56 & 0.55 \\
\hline Num. obs. & 72 & 44 & 72 & 44 \\
\hline
\end{tabular}

Exporter (1-4) and importer (5-8) fixed effects are extracted from a basic gravity regression on differentiated and non-differentiated goods, respectively; the basic equation is equivalent to specification (1) of Sect. 5.1 Standard Gravity. The fixed effects are estimated via OLS following the design of Sect. 5.3 Impact on Average Barriers, but restricted to preference measures for patience and risk. Uneven specifications show the results for GPS data, while even ones use Hofstede dimensions instead

${ }^{* * *} p<0.001,{ }^{* *} p<0.01,{ }^{*} p<0.05,{ }^{\dagger} p<0.1$ 
Table 26 Genetics, religion \& GPS

\begin{tabular}{|c|c|c|c|c|c|}
\hline & \multirow{2}{*}{$\begin{array}{l}\text { Single Pref. Dist. } \\
\text { (1) }\end{array}$} & \multicolumn{2}{|l|}{ Gen. Dist. } & \multicolumn{2}{|l|}{ Rel. Dist. } \\
\hline & & (2) & (3) & (4) & (5) \\
\hline \multirow[t]{2}{*}{ ldist } & $-0.59^{* * *}$ & $-0.69^{* * *}$ & $-0.68^{* * *}$ & $-0.59^{* * *}$ & $-0.60^{* * *}$ \\
\hline & $(0.06)$ & $(0.09)$ & $(0.08)$ & $(0.06)$ & $(0.06)$ \\
\hline \multirow[t]{2}{*}{ contig } & $0.48^{* * *}$ & $0.38^{* *}$ & $0.37^{* *}$ & $0.48^{* * *}$ & $0.49^{* * *}$ \\
\hline & $(0.14)$ & $(0.13)$ & $(0.13)$ & $(0.13)$ & $(0.14)$ \\
\hline \multirow[t]{2}{*}{ colony } & $0.33^{* *}$ & $0.40^{* * *}$ & $0.39^{* * *}$ & $0.33^{* *}$ & $0.34^{* * *}$ \\
\hline & $(0.10)$ & $(0.10)$ & $(0.10)$ & $(0.10)$ & $(0.10)$ \\
\hline \multirow[t]{2}{*}{ rta } & $0.35^{* * *}$ & $0.34^{* * *}$ & $0.33^{* * *}$ & $0.35^{* * *}$ & $0.35^{* * *}$ \\
\hline & $(0.09)$ & $(0.09)$ & $(0.09)$ & $(0.09)$ & $(0.09)$ \\
\hline \multirow[t]{2}{*}{$\operatorname{lng}$} & -0.06 & -0.06 & -0.04 & -0.06 & -0.06 \\
\hline & $(0.13)$ & $(0.13)$ & $(0.13)$ & $(0.13)$ & $(0.12)$ \\
\hline \multirow[t]{2}{*}{ comleg } & $0.15^{*}$ & $0.15^{*}$ & $0.15^{*}$ & $0.16^{*}$ & $0.16^{*}$ \\
\hline & $(0.07)$ & $(0.07)$ & $(0.07)$ & $(0.07)$ & $(0.07)$ \\
\hline \multirow[t]{2}{*}{ leg.qlt } & $0.15^{* * *}$ & $0.14^{* * *}$ & $0.14^{* * *}$ & $0.15^{* * *}$ & $0.15^{* * *}$ \\
\hline & $(0.03)$ & $(0.03)$ & $(0.03)$ & $(0.03)$ & $(0.03)$ \\
\hline \multirow[t]{2}{*}{ dpati } & -0.16 & -0.13 & -0.14 & -0.16 & -0.16 \\
\hline & $(0.10)$ & $(0.10)$ & $(0.10)$ & $(0.10)$ & $(0.11)$ \\
\hline \multirow[t]{2}{*}{ drisk } & $0.52^{\dagger}$ & $0.48^{\dagger}$ & $0.47^{\dagger}$ & $0.52^{\dagger}$ & $0.51^{\dagger}$ \\
\hline & $(0.28)$ & $(0.27)$ & $(0.27)$ & $(0.28)$ & $(0.27)$ \\
\hline \multirow[t]{2}{*}{ dposrec } & -0.04 & 0.03 & 0.01 & -0.03 & -0.02 \\
\hline & $(0.18)$ & $(0.17)$ & $(0.17)$ & $(0.17)$ & $(0.17)$ \\
\hline \multirow[t]{2}{*}{ dnegrec } & $-0.53^{* *}$ & $-0.53^{* *}$ & $-0.52^{* * *}$ & $-0.54^{* *}$ & $-0.55^{* *}$ \\
\hline & $(0.16)$ & $(0.16)$ & $(0.16)$ & $(0.17)$ & $(0.18)$ \\
\hline \multirow[t]{2}{*}{ new_gendist_weighted } & & 7.92 & & & \\
\hline & & $(5.08)$ & & & \\
\hline \multirow[t]{2}{*}{ new_gendist_plurality } & & & $6.95^{\dagger}$ & & \\
\hline & & & $(4.04)$ & & \\
\hline \multirow[t]{2}{*}{ reldist_dominant_formula } & & & & 0.04 & \\
\hline & & & & $(0.10)$ & \\
\hline \multirow[t]{2}{*}{ reldist_weighted_formula } & & & & & 0.26 \\
\hline & & & & & $(0.29)$ \\
\hline Observations & 5112.00 & 4970.00 & 4970.00 & 4970.00 & 4970.00 \\
\hline Deviance & $4562 \times 10^{9}$ & $4495 \times 10^{9}$ & $4489 \times 10^{9}$ & $4548 \times 10^{9}$ & $4542 \times 10^{9}$ \\
\hline Null Deviance & $52347 \times 10^{9}$ & $51781 \times 10^{9}$ & $51781 \times 10^{9}$ & $51731 \times 10^{9}$ & $51731 \times 10^{9}$ \\
\hline Exp./Imp. FE & YES & YES & YES & YES & YES \\
\hline
\end{tabular}

The aggregated bilateral exports are estimated via PPML. Models (2) and (3) include genetical distances between populations in two different calculations, whereas specifications (4) and (5) include two version of religious distance. Both distances are taken from Spolaore and Wacziarg (2018) and compared to the GPS' preference distances

${ }^{* * *} p<0.001,{ }^{* *} p<0.01,{ }^{*} p<0.05,{ }^{\dagger} p<0.1$ 
Funding Open Access funding enabled and organized by Projekt DEAL.

Open Access This article is licensed under a Creative Commons Attribution 4.0 International License, which permits use, sharing, adaptation, distribution and reproduction in any medium or format, as long as you give appropriate credit to the original author(s) and the source, provide a link to the Creative Commons licence, and indicate if changes were made. The images or other third party material in this article are included in the article's Creative Commons licence, unless indicated otherwise in a credit line to the material. If material is not included in the article's Creative Commons licence and your intended use is not permitted by statutory regulation or exceeds the permitted use, you will need to obtain permission directly from the copyright holder. To view a copy of this licence, visit http://creativecommons.org/licen ses/by/4.0/.

\section{References}

Aeberhardt, R., Buono, I., \& Fadinger, H. (2014). Learning, incomplete contracts and export dynamics: Theory and evidence from french firms. European Economic Review, 68, 219-249.

Ahn, J. (2011). A theory of domestic and international trade finance. In IMF working papers 11/262, International Monetary Fund.

Akerlof, G. A. (1982). Labor contracts as partial gift exchange. The Quarterly Journal of Economics, 97(4), 543-569.

Anderson, J. E., \& van Wincoop, E. (2003). Gravity with gravitas: A solution to the border puzzle. American Economic Review, 93(1), 170-192.

Antras, P. (2003). Firms, contracts, and trade structure. The Quarterly Journal of Economics, 118(4), $1375-1418$

Antras, P., \& Foley, C. F. (2015). Poultry in motion: A study of international trade finance practices. Journal of Political Economy, 123(4), 853-901.

Araujo, L., Mion, G., \& Ornelas, E. (2016). Institutions and export dynamics. Journal of International Economics, 98, 2-20.

Cable, D. M., \& Shane, S. (1997). A prisoner's dilemma approach to entrepreneur-venture capitalist relationships. The Academy of Management Review, 22(1), 142-176.

Caliendo, M., Fossen, F., \& Kritikos, A. (2012). Trust, positive reciprocity, and negative reciprocity: Do these traits impact entrepreneurial dynamics? Journal of Economic Psychology, 33, 394-409.

Defever, F., Fischer, C., \& Suedekum, J. (2016). Relational contracts and supplier turnover in the global economy. Journal of International Economics, 103, 147-165.

Dohmen, T., Enke, B., Falk, A., Huffman, D. \& Sunde, U. (2016). Patience and the wealth of nations. In Working papers 2016-012, Human Capital and Economic Opportunity Working Group.

Dohmen, T., Falk, A., Huffman, D., \& Sunde, U. (2008). Representative trust and reciprocity: Prevalence and determinants. Economic Inquiry, 46(1), 84-90.

Donaubauer, J., Glas, A., Meyer, B., \& Nunnenkamp, P. (2018). Disentangling the impact of infrastructure on trade using a new index of infrastructure. Review of World Economics, 154(4), 745-784.

Egger, P., \& Larch, M. (2008). Interdependent preferential trade agreement memberships: An empirical analysis. Journal of International Economics, 76(2), 384-399.

Falk, A., Becker, A., Dohmen, T., Enke, B., Huffman, D. B., \& Sunde, U. (2018). Global evidence on economic preferences. The Quarterly Journal of Economics, 133(4), 1645-1692.

Falk, A., Becker, A., Dohmen, T., Huffman, D. B. \& Sunde, U. (2016). The preference survey module: A validated instrument for measuring risk, time, and social preferences. IZA Discussion Papers 9674 , Institute for the Study of Labor (IZA).

Fehr, E., \& Gächter, S. (2000). Fairness and retaliation: The economics of reciprocity. Journal of Economic Perspectives, 14(3), 159-181.

Fehr, E., \& Gächter, S. (2002). Altruistic punishment in humans. Nature, 415(6868), 137.

Fehr, E., Gächter, S., \& Kirchsteiger, G. (1997). Reciprocity as a contract enforcement device: Experimental evidence. Econometrica, 65(4), 833-860.

Felbermayr, G. J., \& Toubal, F. (2010). Cultural proximity and trade. European Economic Review, 54(2), 279-293.

Fensore, I., Legge, S. \& Schmid, L. (2017). Human barriers to international trade. In Economics working paper series 1712, University of St. Gallen, School of Economics and Political Science. 
Frank, J. (2018). The effect of culture on trade over time: New evidence from the GLOBE data set. Tech. rep., Hohenheim Discussion Papers in Business, Economics and Social Sciences.

Freedom House (2018). Aggregate category and subcategory scores, 2003-2018.

Gächter, S., \& Herrmann, B. (2009). Reciprocity, culture and human cooperation: Previous insights and a new cross-cultural experiment. Philosophical Transactions of the Royal Society B: Biological Sciences, 364(1518), 791-806.

Giuliano, P., Spilimbergo, A., \& Tonon, G. (2013). Genetic distance, transportation costs, and trade1. Journal of Economic Geography, 14(1), 179-198.

Guiso, L., Sapienza, P., \& Zingales, L. (2009). Cultural biases in economic exchange? Quarterly Journal of Economics, 124(3), 1095-1131.

Head, K., \& Mayer, T. (2013). What separates us? sources of resistance to globalization. Canadian Journal of Economics, 46(4), 1196-1231.

Head, K., \& Mayer, T. (2014). Gravity equations: Workhorse, toolkit, and cookbook (pp. 131-195). In Handbook of international economics. Elsevier.

Head, K., Mayer, T., \& Ries, J. (2010). The erosion of colonial trade linkages after independence. Journal of International Economics, 81(1), 1-14.

Herrmann, B., Thöni, C. \& Gächter, S. (2008). Antisocial punishment across societies. Science (New York, N.Y.), 319, 1362-7.

Hlavac, M. (2018). stargazer: Well-formatted regression and summary statistics tables.

Hofstede, G., Hofstede, G. J., \& Minkov, M. (2010). Cultures and organizations: Software of the mind. New York: Revised and expanded third edition.

Jaeggi, A., Legge, S., \& Schmid, L. (2018). Dyadic value distance: Determinants and consequences. Economics Letters, 165, 48-53.

Kaufmann, D., Kraay, A. \& Mastruzzi, M. (2009). Governance matters VIII: Aggregate and individual governance indicators 1996-2008. Policy Research Working Papers, The World Bank.

Kihlstrom, R. E., \& Laffont, J.-J. (1979). A general equilibrium entrepreneurial theory of firm formation based on risk aversion. Journal of Political Economy, 87(4), 719-748.

Kukharskyy, B. (2016). Relational contracts and global sourcing. Journal of International Economics, $101,123-147$.

Lameli, A., Nitsch, V., Südekum, J., \& Wolf, N. (2015). Same same but different: Dialects and trade. German Economic Review, 16(3), 290-306.

Leifeld, P. (2013). texreg: Conversion of statistical model output in R to html tables. Journal of Statistical Software, 55(8), 1-24.

Marshall, M. G., Gurr, T. R. \& Jaggers, K. (2018). Polity iv project: Political regime characteristics and transitions, 1800-2017.

Mayer, T., Vicard, V., \& Zignago, S. (2019). The cost of non-Europe, revisited*. Economic Policy, 34(98), 145-199.

Mayer, T., \& Zignago, S. (2011). Notes on CEPII's distances measures: The GeoDist database. Working Papers 2011-2025, CEPII Research Center.

Melitz, J., \& Toubal, F. (2014). Native language, spoken language, translation and trade. Journal of International Economics, 93(2), 351-363.

Niepmann, F., \& Schmidt-Eisenlohr, T. (2017). International trade, risk and the role of banks. Journal of International Economics, 107, 111-126.

Nikiforakis, N. (2008). Punishment and counter-punishment in public good games: Can we really govern ourselves? Journal of Public Economics, 92(1-2), 91-112.

Nunn, N. (2007). Relationship-specificity, incomplete contracts and the pattern of trade. Quarterly Journal of Economics, 122 (2), 569-600, reprinted in D. Bernhofen (ed.), Empirical International Trade, Edward Elgar Publishing, 2010.

Nunn, N., \& Puga, D. (2012). Ruggedness: The blessing of bad geography in Africa. Review of Economics and Statistics, 94(1), 20-36.

Rauch, J. E. (1999). Networks versus markets in international trade. Journal of International Economics, $48(1), 7-35$.

Rauch, J. E., \& Watson, J. (2003). Starting small in an unfamiliar environment. International Journal of Industrial Organization, 21(7), 1021-1042.

Santos Silva, J. M. C., \& Tenreyro, S. (2006). The log of gravity. Review of Economics and Statistics, $88(4), 641-658$.

Santos Silva, J. M. C., Tenreyro, S., \& Wei, K. (2014). Estimating the extensive margin of trade. Journal of International Economics, 93(1), 67-75. 
Spolaore, E., \& Wacziarg, R. (2016). Ancestry, language and culture. In The Palgrave handbook of economics and language. Springer (pp. 174-211).

Spolaore, E., \& Wacziarg, R. (2018). Ancestry and development: New evidence. Journal of Applied Econometrics, 33(5), 748-762.

Stammann, A. (2017). Fast and feasible estimation of generalized linear models with many two-way fixed effects. arXiv preprint arXiv:1707.01815.

Sutter, M., Kocher, M. G., Glätzle-Rützler, D., \& Trautmann, S. T. (2013). Impatience and uncertainty: Experimental decisions predict adolescents field behavior. American Economic Review, 103(1), 510-531.

Trefler, D. (1995). The case of the missing trade and other mysteries. American Economic Review, 85(5), 1029-1046.

Wickham, H. (2016). ggplot2: Elegant graphics for data analysis. New York: Springer.

Wickham, H. François, R., Henry, L. \& Müller, K. (2018). dplyr: A grammar of data manipulation.

Yotov, Y. V., Piermartini, R., Monteiro, J.-A. \& Larch, M. (2016). An advanced guide to trade policy analysis: The structural gravity model. World Trade Organization.

Yu, S., Beugelsdijk, S., \& de Haan, J. (2015). Trade, trust and the rule of law. European Journal of Political Economy, 37, 102-115.

Publisher's Note Springer Nature remains neutral with regard to jurisdictional claims in published maps and institutional affiliations. 